\title{
Technical and Economic Analysis of Energy Efficiency of Chinese Room Air Conditioners
}

\author{
David Fridley, Gregory Rosenquist, Jiang Lin, Li Aixian, Xin Dingguo, \\ and Cheng Jianhong
}

February 2001

Energy Analysis Department

Environmental Energy Technologies Division

Lawrence Berkeley National Laboratory

University of California

Berkeley, CA 94720

and

China National Institute of Standardization (CNIS)

Beijing, China

and

Beijing Energy Efficiency Center (BECon)

Beijing, China

This work was funded by the Climate Protection Division of the U.S. Environmental Protection Agency through the U.S. Department of Energy under Contract No. DE-AC03-76SF00098 


\begin{abstract}
China has experienced tremendous growth in the production and sales of room air conditioners over the last decade. Although minimum room air conditioner energy efficiency standards have been in effect since 1989, no efforts were made during most of the 1990's to update the standard to be more reflective of current market conditions. But in 1999, China's State Bureau of Technical Supervision (SBTS) included in their 1999 plan the development and revision of the 1989 room air conditioner standard. SBTS signed an agreement with Lawrence Berkeley National Laboratory (LBNL) for an air conditioner standards training program, supported by the U.S. Environmental Protection Agency (EPA).

Based on the engineering and life cycle-cost analyses performed, the most predominant type of room air conditioner in the Chinese market (split-type with a cooling capacity between 2500 and $4500 \mathrm{~W}(8500 \mathrm{Btu} / \mathrm{h}$ and $15,300 \mathrm{Btu} / \mathrm{h}))$ can have its efficiency increased cost-effectively to an energy efficiency ratio (EER) of $2.92 \mathrm{~W} / \mathrm{W}(9.9 \mathrm{Btu} / \mathrm{hr} / \mathrm{W})$. If an EER standard of $2.92 \mathrm{~W} / \mathrm{W}$ became effective in 2001, Chinese consumers are estimated to save over 3.5 billion Yuan (420 million U.S. dollars) over the period of 2001-2020. Carbon emissions over the same period would be reduced by approximately 12 million metric tonnes.
\end{abstract}




\section{TABLE OF CONTENTS}

Preface.

1.0 China's Room Air Conditioner Market.

1.1 Future Developments in the Air Conditioner Sector..................................................... 4

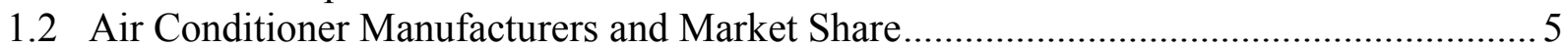

2.0 Characteristics of Room Air Conditioner Technology.................................................. 7

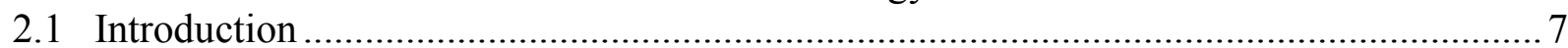

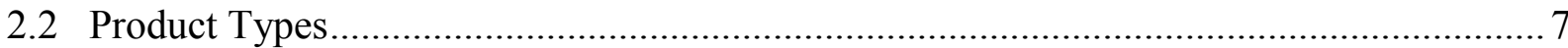

2.3 Evolution of Air Conditioner Market Structure ...................................................... 8

2.4 Air Conditioner Costs and Price Composition ....................................................... 9

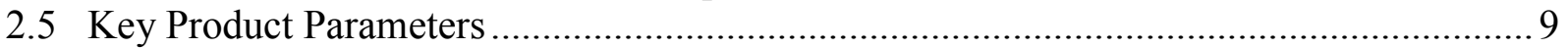

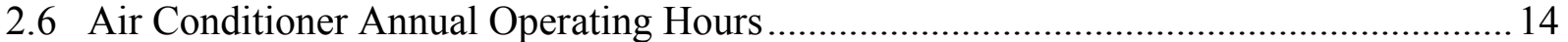

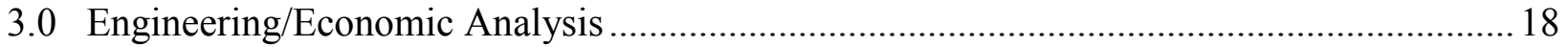

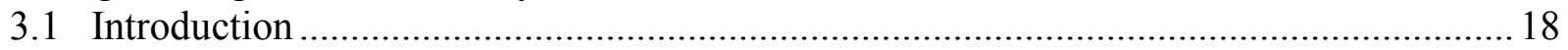

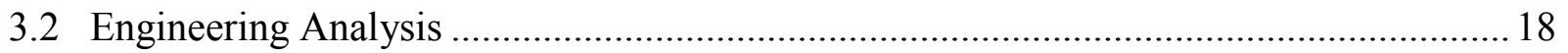

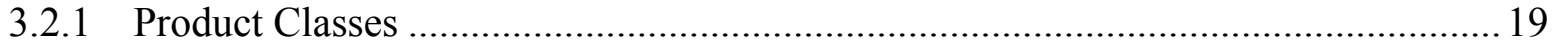

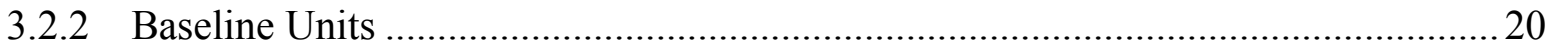

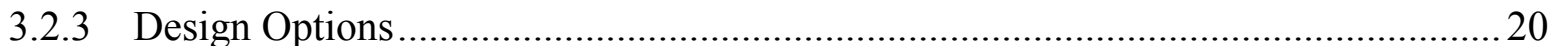

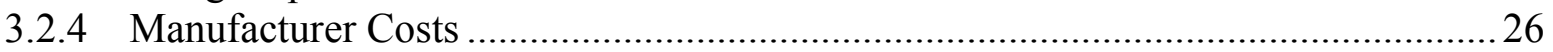

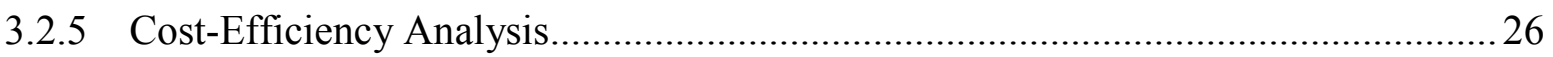

3.2.5.1 Simulation Model ......................................................................................... 27

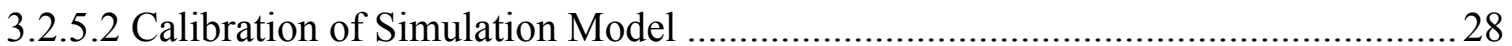

3.2.5.3 Development of New Baseline Unit..................................................... 28

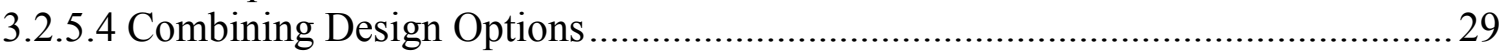

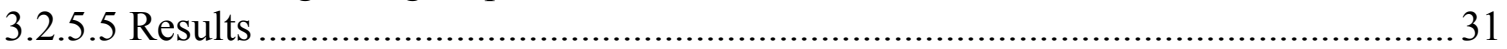

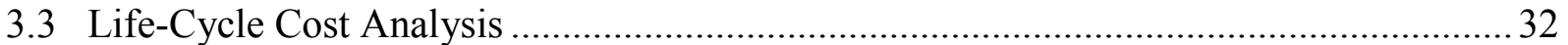

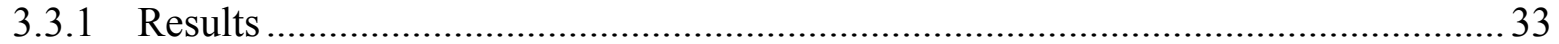

3.4 National Energy Savings and National Economic Impacts .................................... 35

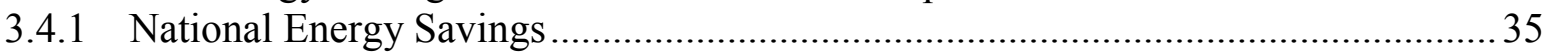

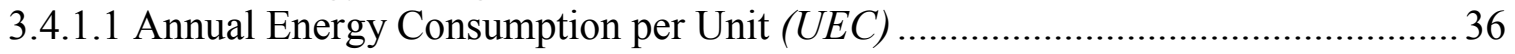

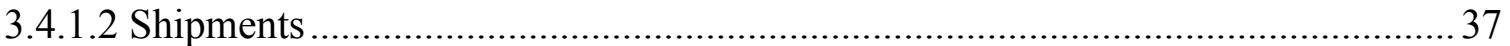

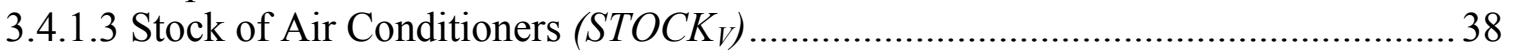

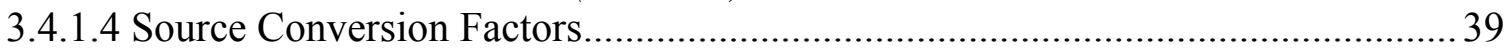

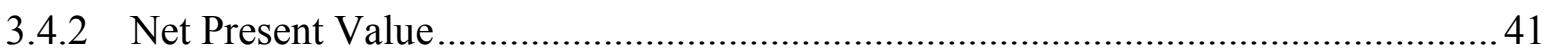

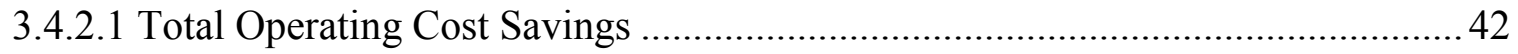

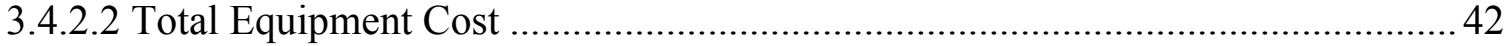

3.4.3 National Energy Savings and Net Present Value Results ....................................43

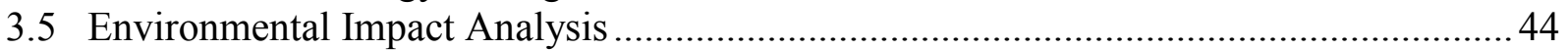

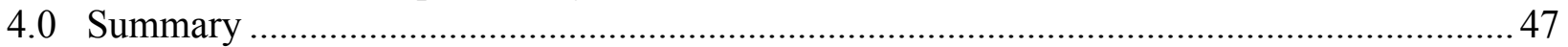

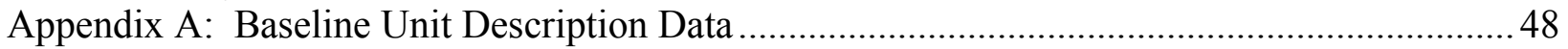

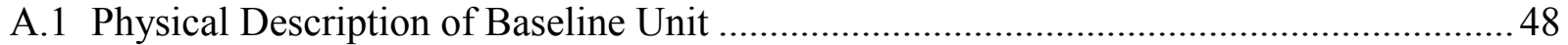

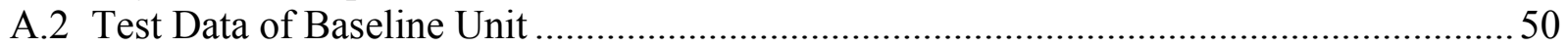

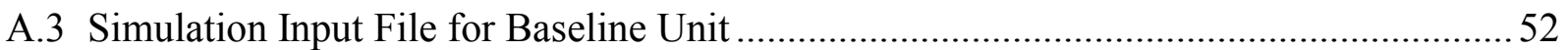

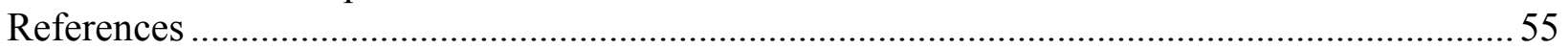




\section{LIST OF FIGURES}

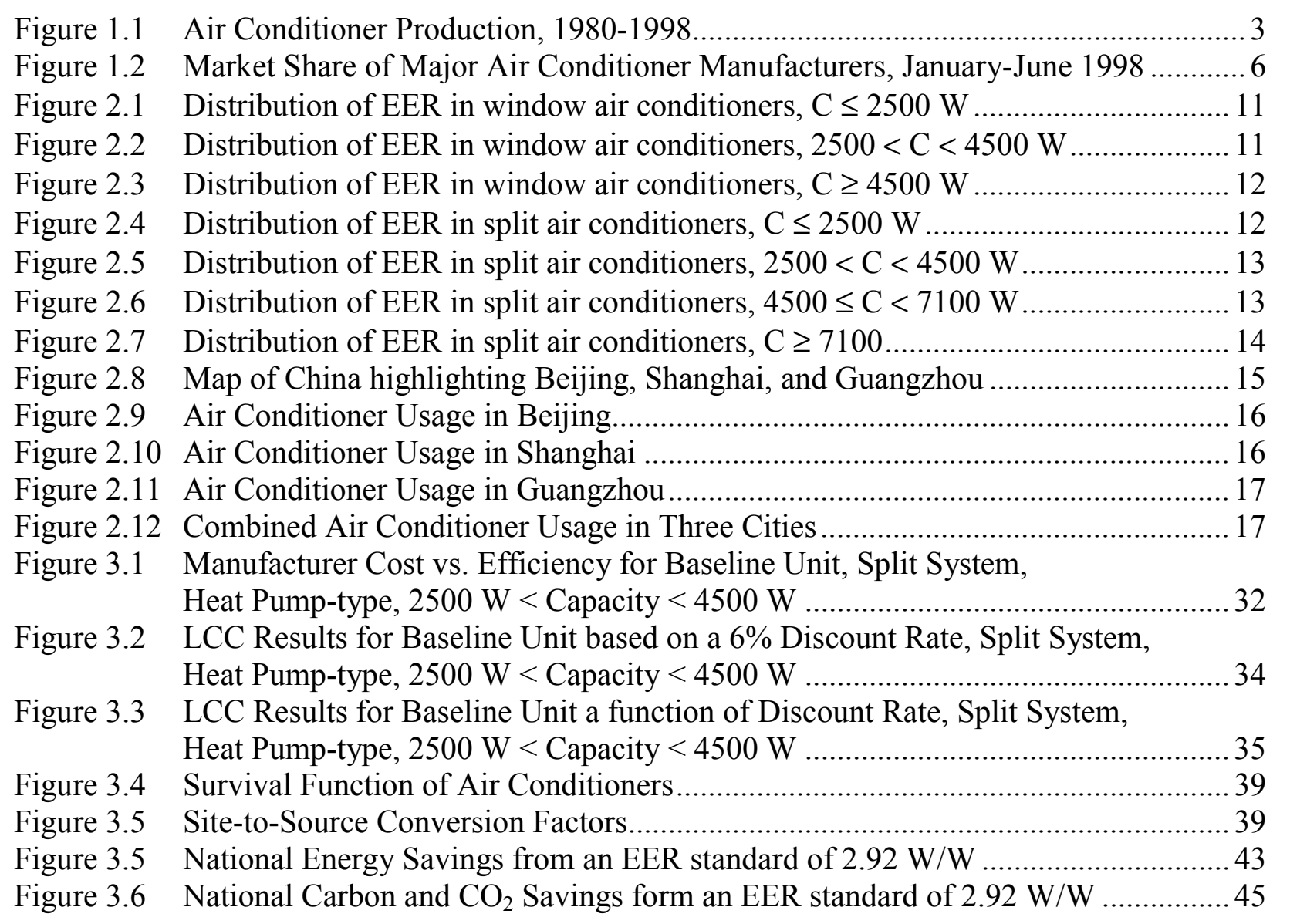




\section{LIST OF TABLES}

Table 1.1 $\quad$ Market Shares of Major Air Conditioner Manufactures.......................................... 5

Table 2.1 Air Conditioner Classifications and Existing Minimum Efficiency Standards..........8

Table 2.2 $\quad$ Production Shares of Air Conditioners .............................................................. 9

Table 3.1 $\quad$ Air Conditioner Product Classes ................................................................... 19

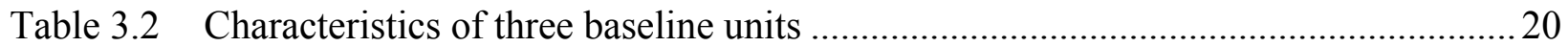

Table 3.3 Design Options for Air Conditioners............................................................... 21

Table $3.4 \quad$ Design Option Manufacturer Costs ............................................................. 26

Table 3.5 Comparison between Test Data and Simulation Results .....................................28

Table $3.6 \quad$ Fin and Tube Heat Transfer and Pressure Enhancement Factors .........................29

Table 3.7 $\quad$ Development of New Baseline Unit ................................................................2.

Table 3.8 Cost-Efficiency Analysis Results for Baseline Unit representing Split System Heat Pump-type, $2500 \mathrm{~W}<$ Capacity < 4500 W Product Class .............................. 31

Table 3.9 Life-Cycle Cost Analysis Results for Baseline Unit, Split System Heat Pump-type, $2500 \mathrm{~W}<$ Capacity < 4500 W .......................................... 33

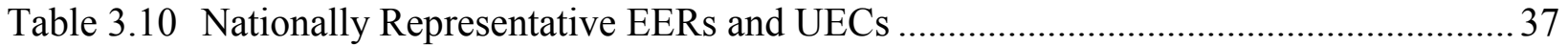

Table 3.11 Chinese Domestic Shipments ...................................................................... 38

Table 3.12 Site-to-Source Conversion Factors …............................................................ 40

Table 3.13 Nationally Representative Equipment Prices and Efficiencies..............................42

Table 3.14 National Energy Savings from an EER standard of 2.92 W/W ..........................43

Table 3.15 Net Present Value of an EER standard of 2.92 W/W ......................................44

Table 3.16 National $\mathrm{CO}_{2}$ and Carbon Savings from an EER standard of $2.92 \mathrm{~W} / \mathrm{W} \ldots \ldots \ldots \ldots \ldots . . . . .45$ 


\section{Preface}

\section{Background to the Project}

In December 1989, the national standard GB12021.3 "Room Air Conditioner Energy Consumption Limits and Testing Methods" established by the National Technical Committee for Energy Basis and Standardization of Management (National Standards Technical Committee, or NSTC for short) was approved by the former State Bureau of Technical Supervision (now the State Bureau of Quality and Technical Supervision) (SBTS 1989). The standard went into effect on 1 December 1990, and was the second of the first eight standards developed for household appliances. At a time when energy was in tight supply in China and the household appliance market was first beginning to take off, the implementation of this standard was effective in stimulating the production of lower energy-consuming air conditioners and encouraging the purchase of higherquality models.

In the ten years since the announcement of the standard, the market for household appliances has grown tremendously along with the growth in the Chinese economy. In particular, the growth in air conditioner ownership has been explosive, and the potential for further growth remains large. Heat pumps, which are air conditioning appliances that provide space-heating in addition to space-cooling, have contributed significantly to the dramatic increase in air conditioner ownership. According to the statistics of China's State Statistical Bureau, production of air conditioners in China grew from 5.2 million in 1995 to 11.6 million in 1998, an increase of nearly 125\%, accounting for about $30 \%$ of world production. The saturation rate for residential air conditioners in urban areas has risen rapidly, though sales of air conditioners in 1999 are expected to moderate to about $3 \%$ growth after jumping $17 \%$ in 1998. Air conditioners are large power consumers, and currently rank with lighting and refrigerators as one of the top three consumers of electricity in households; indeed, during cooling season, air conditioners are the largest power consumer in households.

These developments indicate that some of the technical criteria in the standard announced in 1989 no longer reflect the technical advances since that time, and the standard itself does not accord with the increased emphasis on energy conservation and environmental protection. In addition, the statistical approach used in the original standard and some of prescribed energy consumption limits have become outdated and lag behind international levels. Thus, a complete review of the existing standard is required using transparent analytical techniques, not only to bring China's standard closer in accord with international standards, but also to bring it into greater accord with China's current domestic situation.

The revision of the air conditioner standard has been approved by the State Bureau of Technical Supervision (SBTS) for inclusion in their 1999 plan for standards development and revision. The effort will be supervised by the Technical Committee on Rational Utilization of Electricity of the National Energy Standards Committee. The China Standardization and Information Classification and Coding Institute (now the China National Institute of Standardization, or CNIS) will be responsible for drafting of the revised standard. 


\section{International Cooperation}

After the work to revise GB12021.3 was formally established as a project, SBTS signed an agreement with LBNL for an air conditioner standards training program, supported by US EPA. The agreement covered training by LBNL experts on the application of various models for the use in standards analysis, adapted for China's specific air conditioner market situation. This agreement was the third in a series of cooperative activities between LBNL and SBTS, the first focusing on refrigerator standards training and second on fluorescent lamp ballast standards. The cooperation has been very effective in raising the overall efficiency standard of Chinese household appliances and bringing them closer to those found elsewhere internationally.

According to the agreement between LBNL and SBTS, SBTS sent three experts (head of the standards revision group and main standards drafters) to LBNL in July-August 1998 and MarchApril 1999. This report details the main results of the analysis performed during the second round of training in March-April 1999, and includes a summary of the data and information analysis done in China on behalf of this project.

\section{Outline of Report}

This report is divided into three main sections:

- Market situation for Chinese air conditioners

- Technical issues for room air conditioners

- Engineering, economic and energy impact analysis

In the first section on the air conditioner market, we provide an overview of the development of the Chinese air conditioner market and a forecast of future development. The market share of the current air conditioner manufacturers is also introduced.

In the second section on technical issues, we discuss the classification of Chinese air conditioners and the evolution of product structure over time, cost structure and main technical parameters, and the distribution of air conditioner efficiency and the average annual usage pattern.

In the most important, yet most difficult section of the report on engineering and economic analysis, we first introduce the basic direction of research and analytical methods, focusing on the certification of the baseline data for each product class. We then discuss in detail the engineering simulation model and its calibration, and the development of the technical options to be analyzed for increasing air conditioner efficiency, including the impact on both energy consumption and cooling capacity for each option. We follow this with presentation of the life-cycle cost (LCC) curves based on the engineering simulation model results, from which we analyzed the impact on national energy consumption by adoption of the optimal EER level for the standard and its net economic benefit. Finally, we discuss the main work to be completed under the next stage of work. 


\subsection{China's Room Air Conditioner Market}

China's first air conditioner was produced in 1963 at the Shanghai Refrigerator Factory. Until the mid-1980s, air conditioner usage was limited by the relatively low consumption standards in China and restrictive policies imposed by the power companies. As a result, China's air conditioner industry developed slowly, and the scale of production was small. In 1984, only 60,000 air conditioners were produced nationally.

In the late 1980s, a rapidly rising standard of living and changing attitudes about consumption led to a greater acceptance of air conditioners to provide more comfortable living conditions. The market for air conditioners began a period of rapid growth, characterized by the import of dozens of production lines. In a short period of time, China's air conditioner industry rapidly assumed large scale proportions.

The second stage of development occurred from 1990 to 1995. During this period, there was a great deal of technical development in the industry, and an orderly market gradually rose out of the rising competition at the time. Between 1991 and 1993 alone, air conditioner production grew at a triple-digit rate (Figure 1.1).

Figure 1.1 Air Conditioner Production, 1980-1998

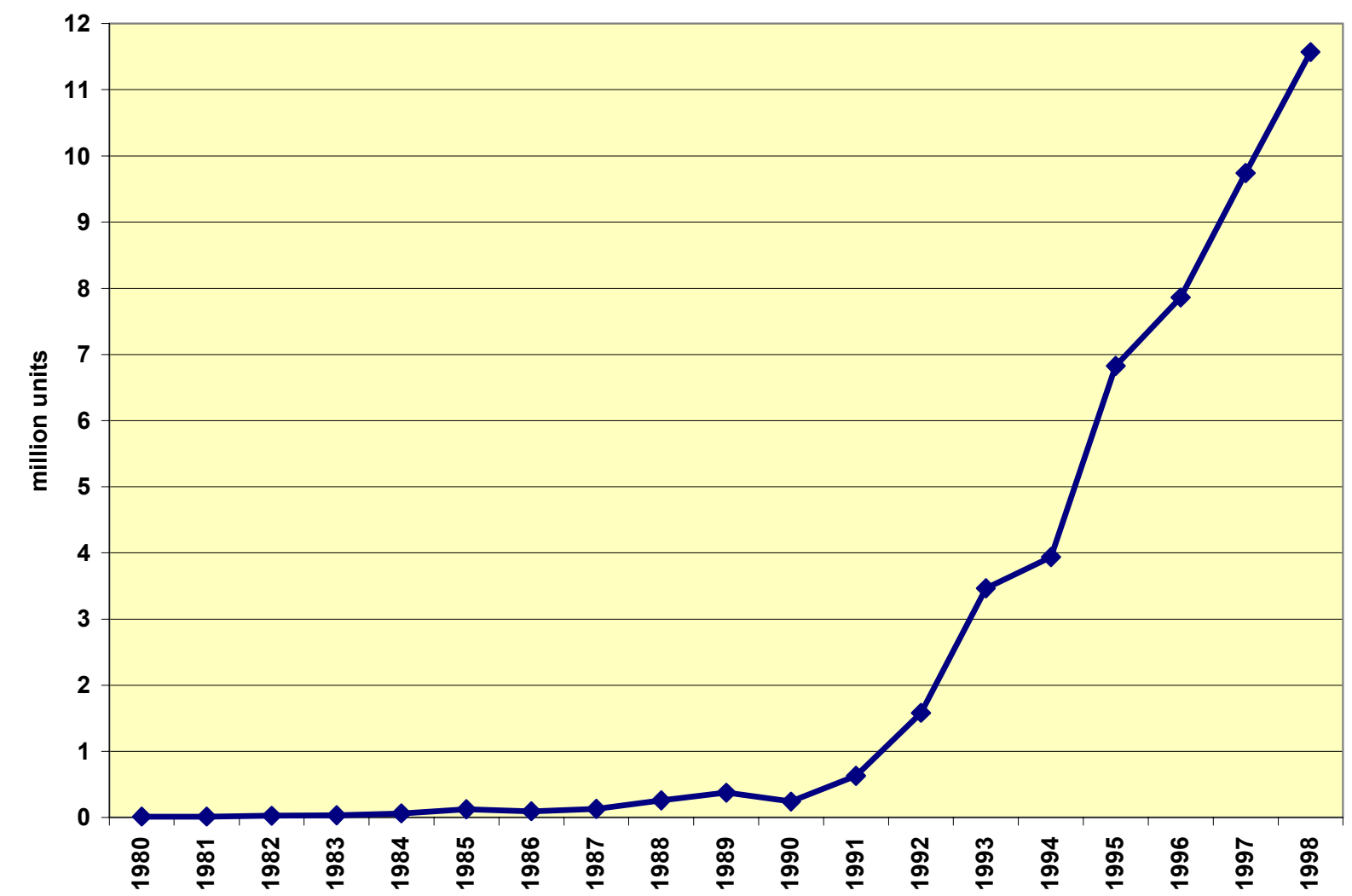

Source: State Statistical Bureau, Zhongguo Gongye Jingji Tongji Nianjian (China Industrial Economic Statistics Yearbook), 1998; Zhongguo Tongji Nianjian 1999 (China Statistical Yearbook, 1999). 
In the early 1990s, the construction of production lines reached its peak. Because the technology involved in air conditioner assembly was not complex and investment requirements were relatively low, many companies entered the air conditioner market, enjoying high profit margins and quick returns on investment. By the mid-1990s, 300 to 400 companies were engaged in air conditioner manufacturer or assembly, some with production no larger than 1000 units per year. A survey conducted in 1993 by the China Light Industry Information Center of the 47 largest manufacturers found that total production capacity had already reached 10.2 million units per year, at a time when demand was about 5 million units per year. With such surplus capacity in place, the market quickly became extremely competitive.

During this period, a few companies with sufficient capital and good production management skills used pricing policy and more advanced technology to raise product quality and improved their sales network and after-sales service system, resulting in a rapid growth of market share. At the same time, most of the small companies without capital and business management expertise went out of business. After 2 to 3 years of consolidation, production capacity dropped, and the air conditioner sector largely centered around 20 large enterprises with the capital, technology, organization, management, and market share to compete effectively with each other.

Since then, the market has become even more competitive, but the strategies for expanding market share have focused on raising the technical quality of the products, concentrating on development of component suppliers, particularly compressors and controls, increasing energy efficiency through use of variable-speed compressors and better controls, lowering the noise level, and better design for air distribution in rooms and personal comfort controls.

\subsection{Future Developments in the Air Conditioner Sector}

Compared to refrigerators and washing machines, air conditioners enjoy greater prospects for market growth. Some of the reasons include:

1. At the end of 1998 , only $20 \%$ of urban households in China owned an air conditioner, compared to $76 \%$ with refrigerators and $91 \%$ with washing machines. Chongqing, Shanghai, and Guangdong lead the nation with air conditioner saturation rates of about 70\%; Guangzhou city alone reported ownership at 104 per 100 households in 1998. In contrast, rural ownership remains at about 1 per 100 households, and many poorer interior provinces have achieved saturation of only $3-10 \%$. Continued high growth in ownership is expected.

2. As people's income continues to rise, air conditioners are gradually becoming a household necessity instead of a luxury good.

3. In some middle and upper-class households, air conditioner ownership has evolved from one air conditioner per household to one air conditioner per room. This trend is expected to continue. 
In addition, China's power companies have begun to invest in the upgrading of the transmission and distribution system, which for many years lagged development in the power generation sector, thus increasing the capacity of supply to households. The reform of the power sector, the deregulation of electricity supply, and the abolition of limits on household electricity use all support further growth in air conditioner use. Considering all of the stimuli to air conditioner use, it is expected that annual domestic demand for air conditioners will reach 10 million units per year after 2000, and domestic production will continue expansion as export demand grows.

\subsection{Air Conditioner Manufacturers and Market Share}

Competition and consolidation in the last few years has resulted in a more highly concentrated air conditioner sector. According to the China Light Industry Information Center, in 1999 there were nine manufacturers with production capacity of 1 million or more units per year, accounting for $61 \%$ of total national production capacity of 20.7 million (CECA 1999). Concentration of production, however, is even higher: in 1998, the top 5 firms produced $65 \%$ of total output, while the top ten firms accounted for $84 \%$ of the total. The utilization rate of production capacity is fairly low. With output reaching 11.57 million in 1998, utilization reached only $56 \%$.

Currently, the leading domestic air conditioner companies include Chulan Group, Gree (Geli) Electrical, Haier Group, Meidi Group, Kelong Group (now merged with Wanbao Air Conditioner), and the Hualing Group. Each of these companies have steadily increased market share through measures such as higher investment in technology, adjustment of the product line, and commitment to quality. The domestic manufacturers also compete with international companies, which have established a number of joint venture enterprises. The major joint venture companies include Mitsubishi and Mitsubishi Heavy Industry, Hitachi, Sharp, Daikin, LG, Matsushita (National), and Sanyo. The market share of the international joint venture companies has been rising as well. The changing market share of the leading companies is provided in Table 1.1, and Figure 1.2 illustrates the market share situation in the first half of 1998, as provided by the China Light Industry Information Center (CLIIC 1998).

Table 1.1 Market Shares of Major Air Conditioner Manufactures

\begin{tabular}{|l|c|c|c|}
\hline & $\mathbf{1 9 9 3}$ & $\mathbf{1 9 9 5}$ & $\mathbf{1 9 9 7}$ \\
\hline Chunlan & $20 \%$ & $24 \%$ & $17 \%$ \\
\hline Huabao & $13 \%$ & $4 \%$ & $12 \%$ \\
\hline Meidi & $8 \%$ & $7 \%$ & $9 \%$ \\
\hline Gree & $5 \%$ & $11 \%$ & $16 \%$ \\
\hline Hongxiang & $5 \%$ & $3 \%$ & - \\
\hline Jiangnan & $5 \%$ & $4 \%$ & - \\
\hline Aite & $5 \%$ & $4 \%$ & - \\
\hline Dongbao & $4 \%$ & $3 \%$ & $7 \%$ \\
\hline Kelong & $4 \%$ & $6 \%$ & $8 \%$ \\
\hline Haier & $3 \%$ & $6 \%$ & $16 \%$ \\
\hline Joint-ventures & - & - & $15 \%$ \\
\hline Others & $28 \%$ & $28 \%$ & - \\
\hline
\end{tabular}


Figure 1.2 Market Share of Major Air Conditioner Manufacturers, January-June 1998

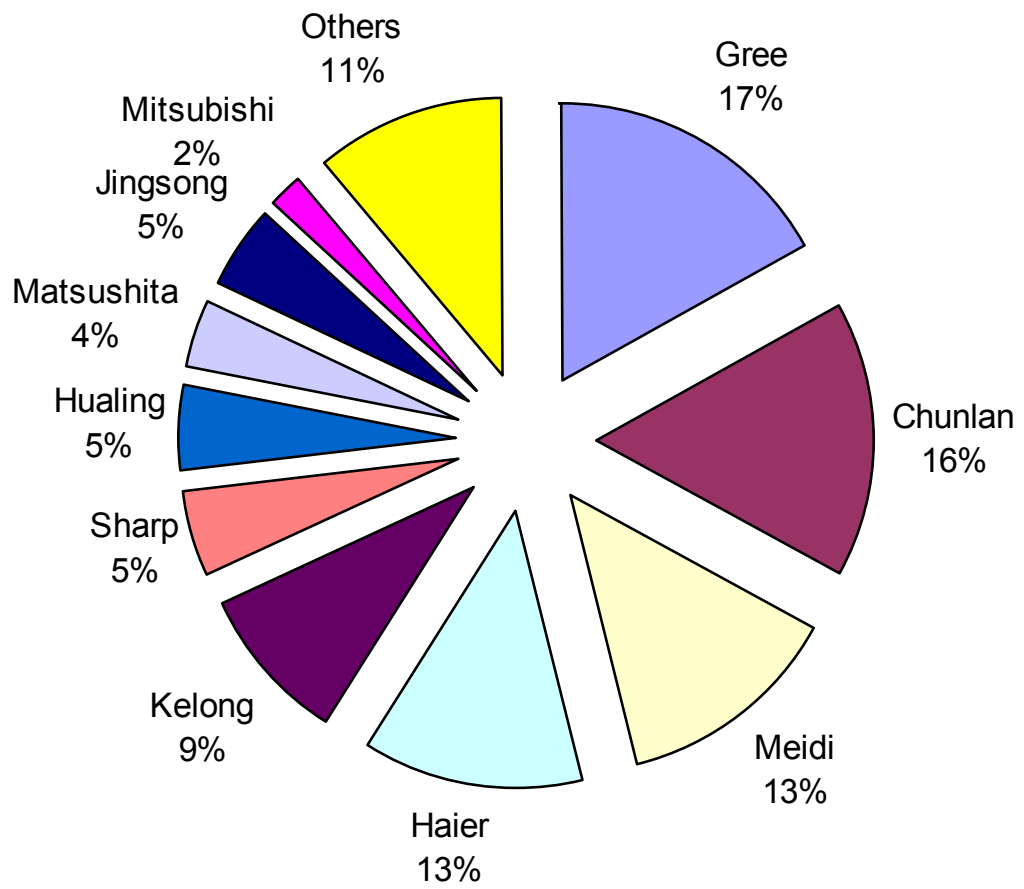




\subsection{Characteristics of Room Air Conditioner Technology}

\subsection{Introduction}

As a tool to modify the natural environment, air conditioning has very broad application. Room air conditioners are one type of air conditioning unit used in a room or other enclosed space to increase the comfort of the environment. It functions by modifying the temperature, humidity, cleanliness, freshness and air flow in a room or enclosed space to maintain the comfort zone for humans or requirements of a technical process.

Room air conditioners contain a compressor, condenser, evaporator, and expansion valve (e.g., capillary tube) as the primary functional components, joined by tubing in a closed system. The refrigerant circulates within the system, cooling at high ambient temperatures, and, in heat-pump systems, heating at lower ambient temperatures, in order to provide room comfort.

\subsection{Product Types}

The Room Air Conditioner Energy Consumption Limits and Testing Methods GB12021.3 of 1989 defined products types based on product structure at the time. Six product types were defined based on the configuration of the unit (split or window-type) and the cooling capacity in thermal Watts (less than $2500 \mathrm{~W}$, greater than $2500 \mathrm{~W}$ and less than $4500 \mathrm{~W}$, and greater than $4500 \mathrm{~W})$.

Since that time, the demand for air conditioners has risen rapidly along with household income, and the air conditioner industry entered a period of rapid development. Technical change and change in consumers' usage patterns and needs resulted in continual change in offerings by air conditioner manufacturers and an increasing number of model types. In 1996, China issued GB/T7725 "Room Air Conditioners" (adapted from ISO5151-94 "Testing and Measurement of Ductless Air Conditioners and Heat Pumps") as a new product standard for air conditioners, rating air conditioners into the following types (SBTS 1996; ISO 1994):

1. According to climate conditions:

Class

$\mathrm{T} 1$

$\mathrm{T} 2$

T3

\section{Maximum Cooling Capacity Test Conditions}

$35^{\circ} \mathrm{C}$

$27^{\circ} \mathrm{C}$

$46^{\circ} \mathrm{C}$

2. According to structural type:

Single-Package: including window, through-the-wall, and mobile.

Split: divided between indoor and outside sets; indoor sets can be subdivided as ceiling, wall, floor, skylight, and imbedded types. 
3. According to function:

Cooling type: cooling only

Heat-pump type: including cooling with heat-pump, cooling with heat-pump and auxiliary electric heating element; and cooling with heat-pump and electric heating element with electric heating converter used in tandem with heat-pump.

Electric heater type: cooling with electric heating component.

The focus of the current standard revision is the energy efficiency ratio of air conditioners, or EER. The EER is the ratio between the cooling capacity of an air conditioner running in cooling mode and the effective input power, under standardized operating conditions. This study does not take into account the heating performance (as measured by the coefficient of performance) for models that are heat pumps. Based on the availability of air conditioner product types on the market, 14 types of air conditioners have been defined based on the classification methodology in GB/T7725 (Table 2.1). The existing minimum EER standards (based on GB12021.3) for each product class are also provided in the table below. Note that since GB12021.3 establishes minimum standards for only six air conditioner product classes, the standards for heat pump-type systems are identical to those for air conditioners (cooling-only units).

Table 2.1 Air Conditioner Classifications and Existing Minimum Efficiency Standards

\begin{tabular}{|c|c|c|c|c|}
\hline \multirow{2}{*}{$\begin{array}{c}\text { Rating Cooling } \\
\text { Capacity, C }\end{array}$} & \multicolumn{2}{|c|}{ Single-package } & \multicolumn{2}{c|}{ Split } \\
\cline { 2 - 5 } Watts & Cooling-only & Heat pump & Cooling-only & Heat pump \\
\hline $\mathrm{C} \leq 2500$ & 2.20 & $W / W$ & $W / W$ & 2.30 \\
\hline $2500<\mathrm{C}<4500$ & 2.26 & 2.20 & 2.30 & 2.37 \\
\hline $4500 \leq \mathrm{C}<7100$ & 2.32 & 2.26 & 2.37 & 2.44 \\
\hline $\mathrm{C} \geq 7100$ & NA & 2.32 & 2.44 & 2.44 \\
\hline
\end{tabular}

In Table 2.1, "single-package" most commonly refers to window-type air conditioners and heat pumps, and "split" commonly refers to wall-mounted splits and cabinet splits; cabinet splits for the most part are concentrated in the greater than $7100 \mathrm{~W}$ capacity category.

Air conditioners with variable-speed motors or compressors are not considered as a separate product class in this revision because of the lack of an internationally recognized testing method. In addition, since the use of variable-speed compressors allows for more efficient operation of the air conditioner, on the order of $15-40 \%$ higher energy savings than single-speed systems (Bahel 1989; Henderson 1990; Hori 1985), it is not necessary at the moment to designate a minimum energy performance standard for this type of equipment.

\subsection{Evolution of Air Conditioner Market Structure}

The Chinese air conditioner market is dominated by window and split-type models, with the latter primarily of the wall type. In the early stage of market development, window type air conditioners predominated, accounting for $63 \%$ of production in 1990. During the 1990s, the market for split air conditioners grew rapidly, and by 1993, production share had overtaken the window type. Since 1995, production of window-type systems has continued on a downward trend, while production of split and cabinet-type equipment has steadily increased. 
Using a dataset of 280 models of 12 brands provided by manufacturers to CNIS in 1998, splittype equipment now account for more than $70 \%$ of production, while single-package equipment account for only $26.3 \%$. Of the split models, $43 \%$ were in the $2500-4500 \mathrm{~W}$ capacity range, more than $10 \%$ higher than all the other split types combined. The distribution of capacity size for window air conditioners is similar to that of splits, the highest share being in the 2500-4500 W range (Table 2.2).

Table 2.2 Production Shares of Air Conditioners

\begin{tabular}{|c|c|c|c|}
\hline & $\begin{array}{c}\text { Rated Cooling Capacity, C } \\
(\mathbf{W})\end{array}$ & \multirow{2}{*}{$\begin{array}{c}\text { Share } \\
\mathbf{( \% )}\end{array}$} & $\begin{array}{c}\text { Share } \\
(\mathbf{\%})\end{array}$ \\
\hline \multirow{2}{*}{$\begin{array}{c}\text { Single-Package } \\
\text { Air Conditioners } \\
\text { (includes heat pumps) }\end{array}$} & $\mathrm{C} \leq 2500$ & 6.2 & \multirow{2}{*}{26.3} \\
\cline { 2 - 3 } & $2500<\mathrm{C}<4500$ & 17.1 & \\
\hline \multirow{2}{*}{$\begin{array}{c}\text { Split } \\
\text { Air Conditioners } \\
\text { (includes heat pumps) }\end{array}$} & $\mathrm{C} \geq 4500$ & 2.9 & \multirow{2}{*}{73.7} \\
\cline { 2 - 3 } & $\mathrm{C} \leq 2500$ & 3.5 & \multirow{2}{*}{} \\
\cline { 2 - 3 } & $2500<\mathrm{C}<4500$ & 19.1 & \\
\hline
\end{tabular}

\subsection{Air Conditioner Costs and Price Composition}

In China, air conditioners are sold primarily through the following three channels:

- Manufacturer $\rightarrow$ Local Distributor (Specialty Retailer) $\rightarrow$ Consumer

- Manufacturer $\rightarrow$ Local Distributor $\rightarrow$ Department Store $\rightarrow$ Consumer

- Manufacturer $\rightarrow$ Local Distributor $\rightarrow$ Consumer

Manufacturers prepare production plans based on market forecasts provided by local distributors, contracts with major department stores, and contingencies for demand shifts. Products are then shipped to major distribution areas, from which distributors arrange delivery to retailers or directly sell to consumers.

According to industry insiders, the manufacturers' cost of production accounts for about $49 \%$ of the consumer's cost of an air conditioner. Included in the manufacturer's cost are the raw materials, manufacturing costs, labor and equipment depreciation.

\subsection{Key Product Parameters}

The key technical parameters for air conditioners include:

- Cooling capacity

- Heating capacity

- Power consumption 
- EER

- Coefficient of performance

- Climate rating

- Air flow

- Noise

- Dehumidification

From the point of view of establishing energy efficiency standards and operation by end-user, the main technical parameters are:

1. Heating and cooling capacity. The total amount of cooling (heating) provided to an enclosed area within a specified unit of time specified in thermal Watts $\left(\mathrm{W}_{\mathrm{th}}\right)$.

2. Power consumption. The total amount of power consumed while operating in cooling or heating mode specified in electrical Watts $\left(\mathrm{W}_{\text {elec }}\right)$.

3. EER: As defined earlier, the ratio between the cooling capacity and total power input, specified in $\mathrm{W}_{\text {th }} / \mathrm{W}_{\text {elec }}$.

4. Coefficient of performance. Under specified conditions, when operating in heat pump mode, the ratio between the heat output and the total power input, specified in $\mathrm{W} / \mathrm{W}$.

5. Air flow. Under rated conditions in cooling mode, the volume of air flow into an enclosed room within a specified period of time.

6. Noise and Dehumidification. These two items are directly related to the comfort of the end-users. The main source of noise in an air conditioner is the fan and the compressor; the dehumidification capacity measures the amount of latent heat (i.e., humidity) removed from the enclosed space.

Using the data provided by manufacturers to CNIS, Figures 2.1 to 2.7 show the distribution of air conditioner EER by equipment type. These performance data reported by manufacturers are derived from third-party testing and verification. According to the standards procedure, every manufacturer has to submit three units of each model produced to one of the two nationally certified testing laboratories: either the China Household Electrical Appliance Research Institute (CHEARI) in Beijing, or the Guangzhou Electrical Appliance Research Institute (GEARI) in Guangzhou. Only after CHEARI or GEARI have certified that the manufacturer reported data matches their test results (i.e., to within $15 \%$ of the allowable tolerance range) do the manufacturers get a production permit for the model. Of the entire dataset of 280 models, the average EER of single-package air conditioners is 2.47 , while that of split air conditioners is 2.70 . For single-package air conditioners of less than 2500 or greater than $4500 \mathrm{~W}$ cooling capacity, the minimum EER is 2.30, close to the minimum energy consumption limit established in GB12021.3-89. For those in the 2500 to 4500 range, the minimum efficiency is 2.26 , about $8 \%$ lower than the minimum in GB12021.3-89. For split air conditioners, the lowest recorded EERs are all above the minimum in GB12021.3-89. This demonstrates the uneven development of air 
conditioner technology. For the primary product in the market - the room split - technology has improved steadily, while it has been difficult to improve technology in single-package models.

Figure 2.1 Distribution of EER in window air conditioners, $C \leq 2500 \mathrm{~W}$

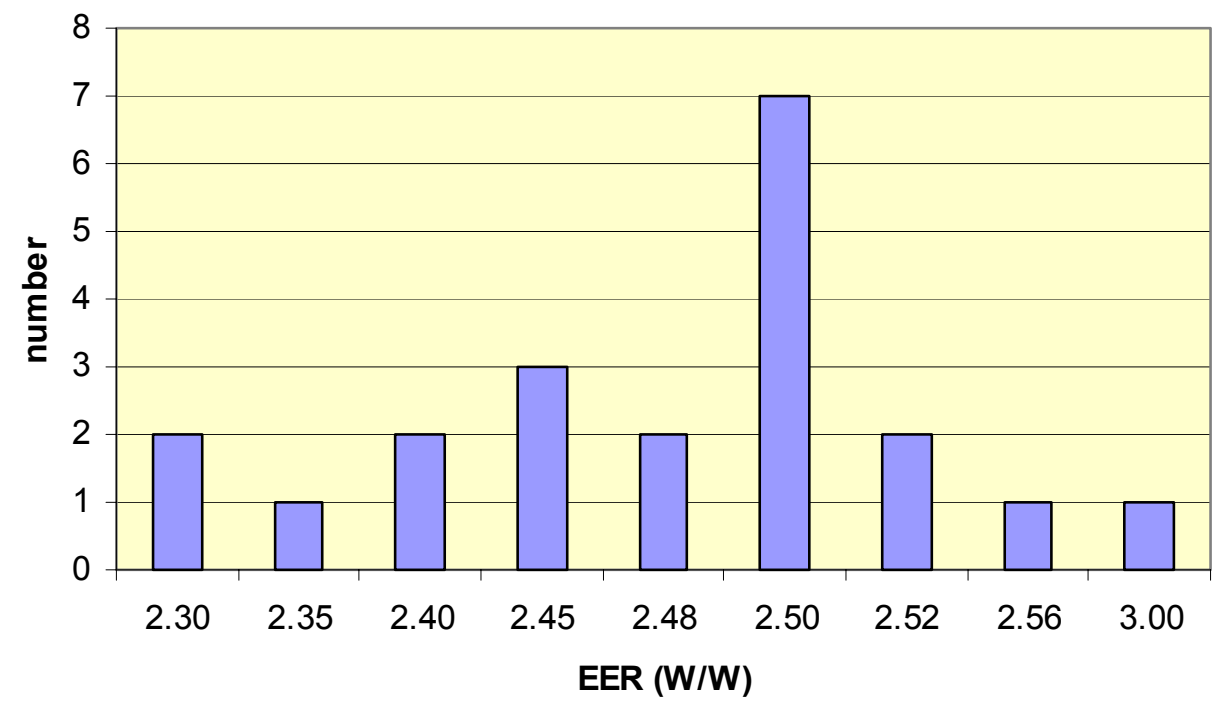

Figure 2.2 Distribution of EER in window air conditioners, $2500<\mathrm{C}<4500 \mathrm{~W}$

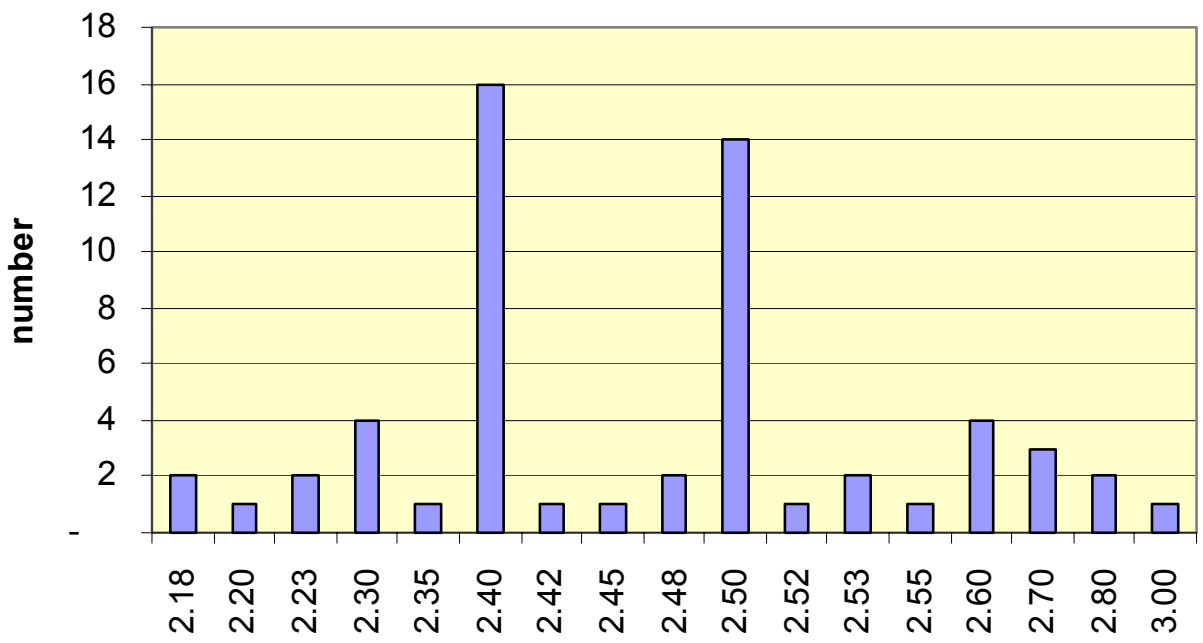

EER (W/W) 
Figure 2.3 Distribution of EER in window air conditioners, $C \geq 4500 \mathrm{~W}$

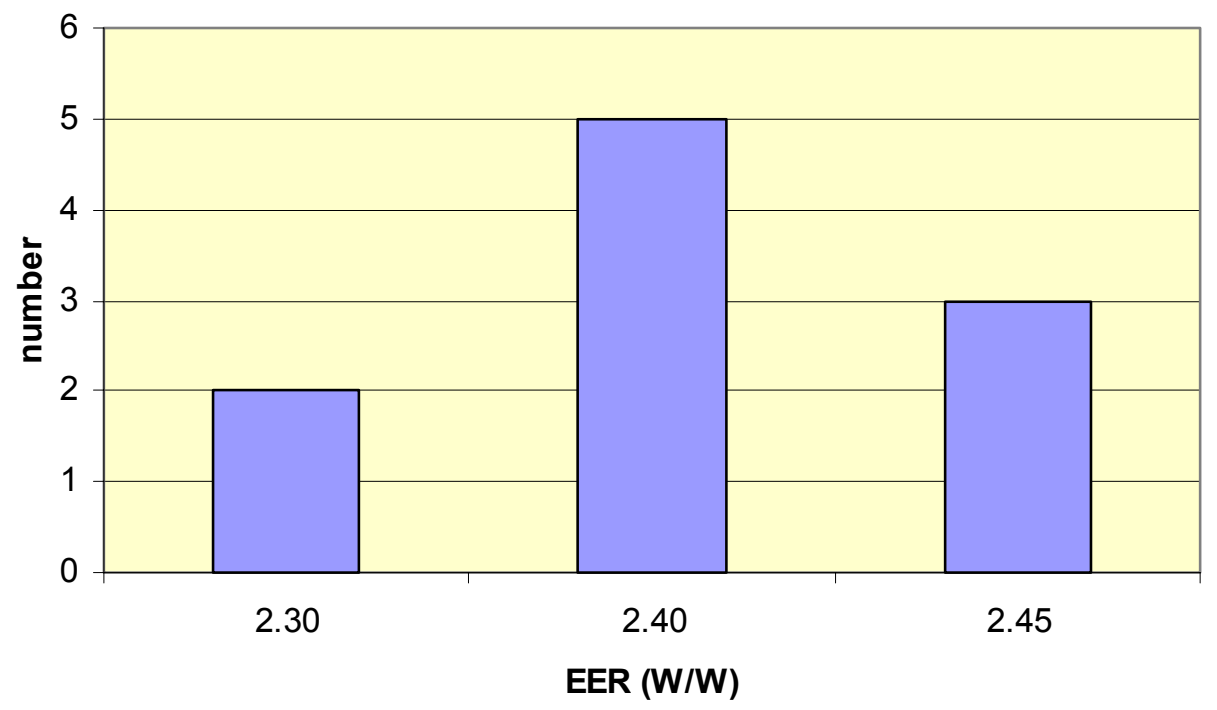

Figure 2.4 Distribution of EER in split air conditioners, $C \leq 2500 \mathrm{~W}$

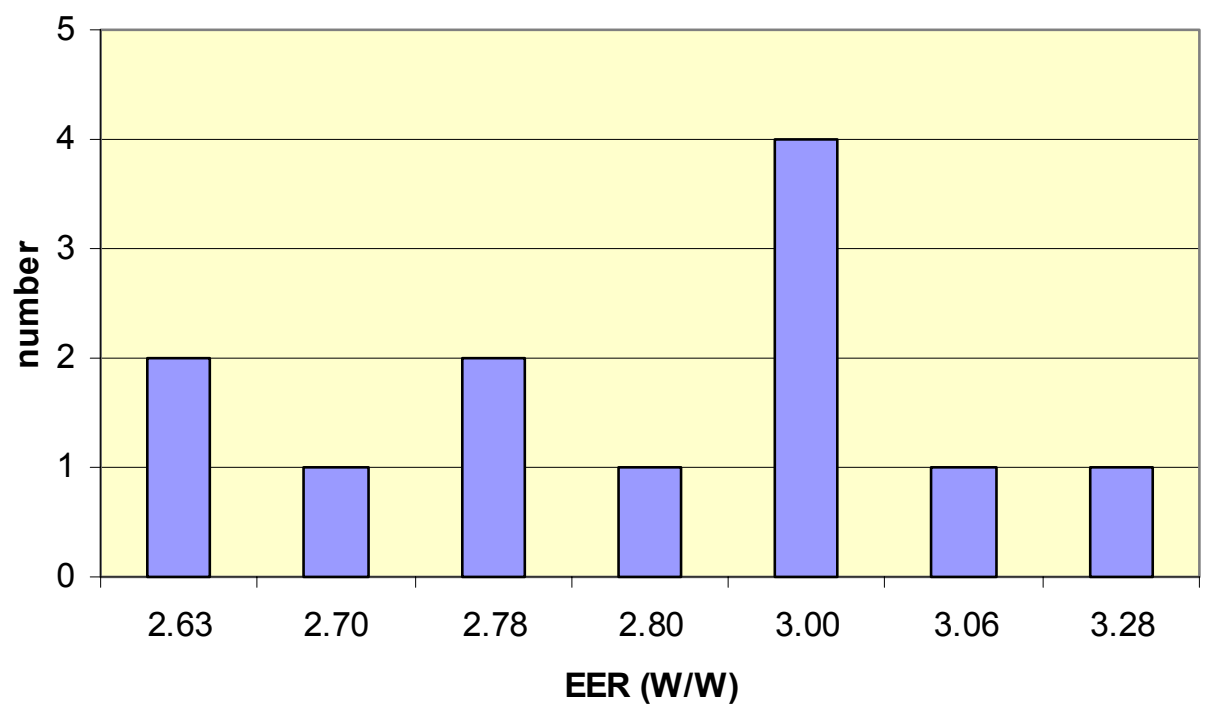


Figure 2.5 Distribution of EER in split air conditioners, $2500<\mathrm{C}<4500 \mathrm{~W}$

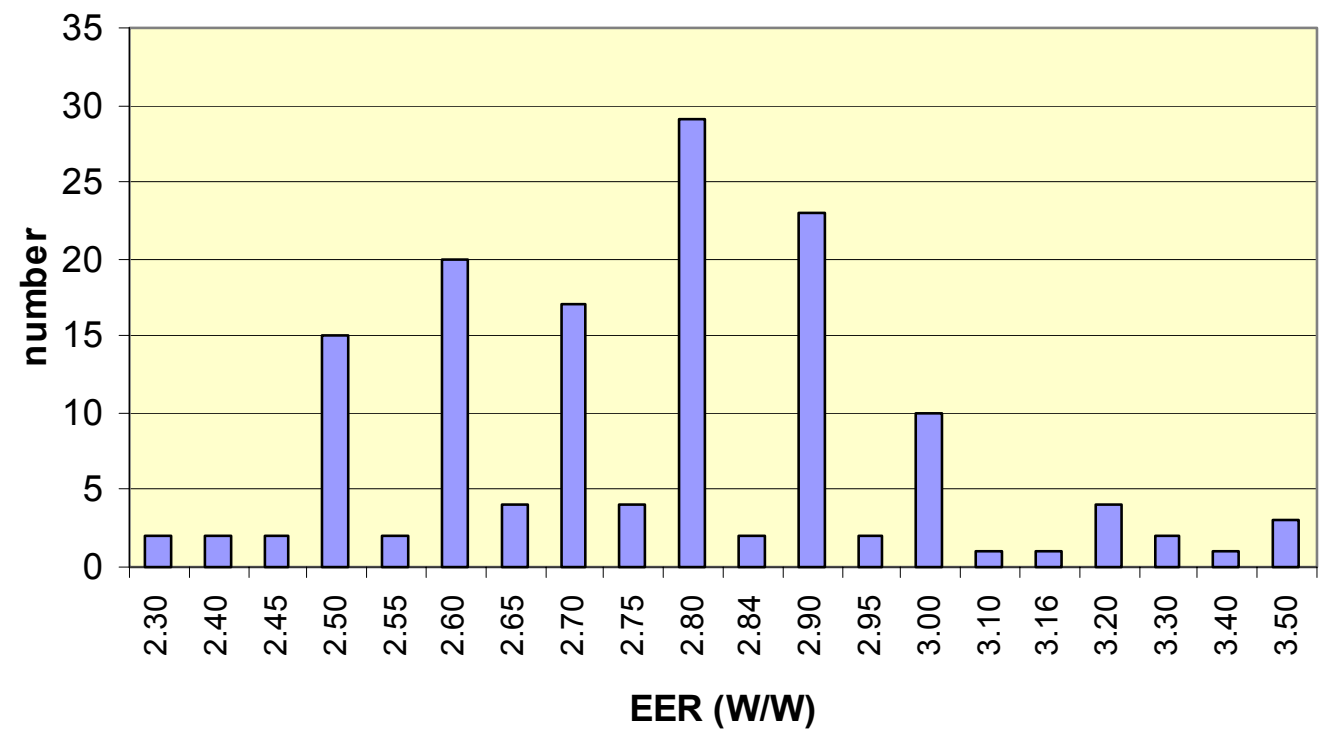

Figure 2.6 Distribution of EER in split air conditioners, $4500 \leq \mathrm{C}<7100 \mathrm{~W}$

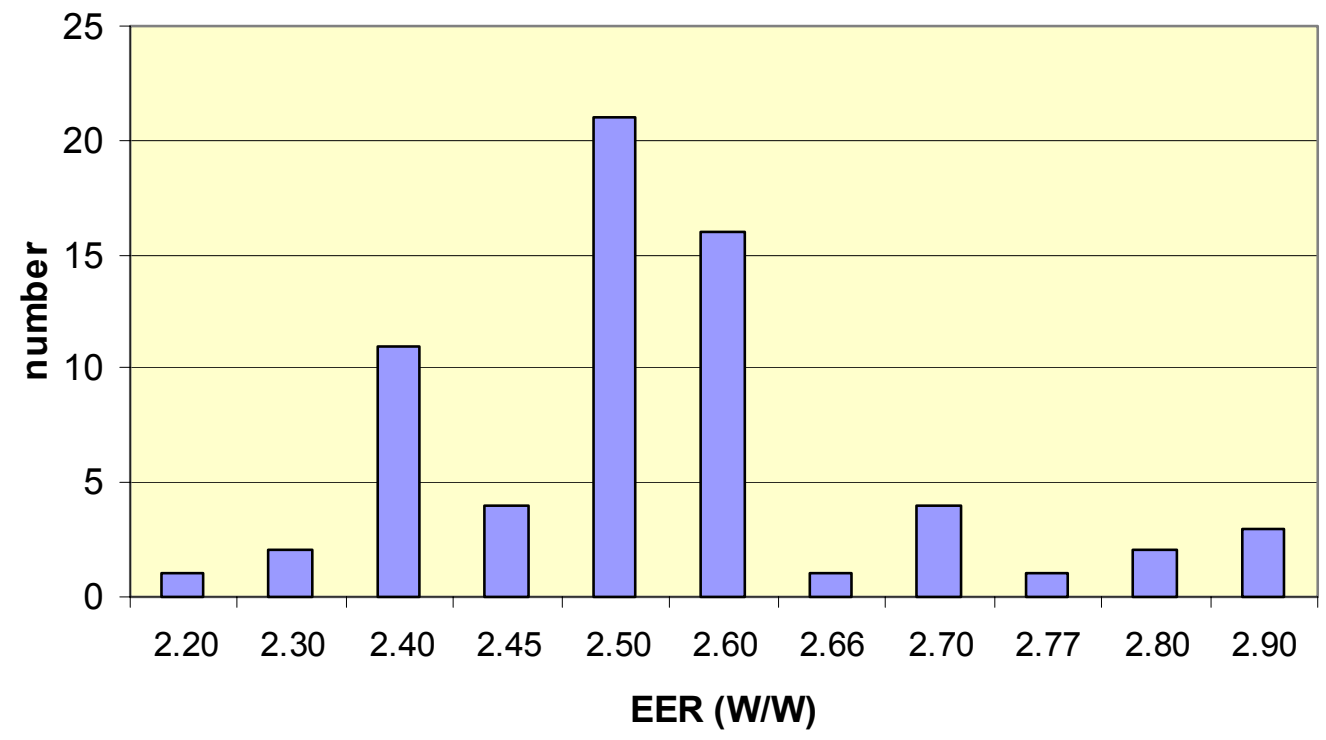


Figure 2.7 Distribution of EER in split air conditioners, $C \geq 7100$

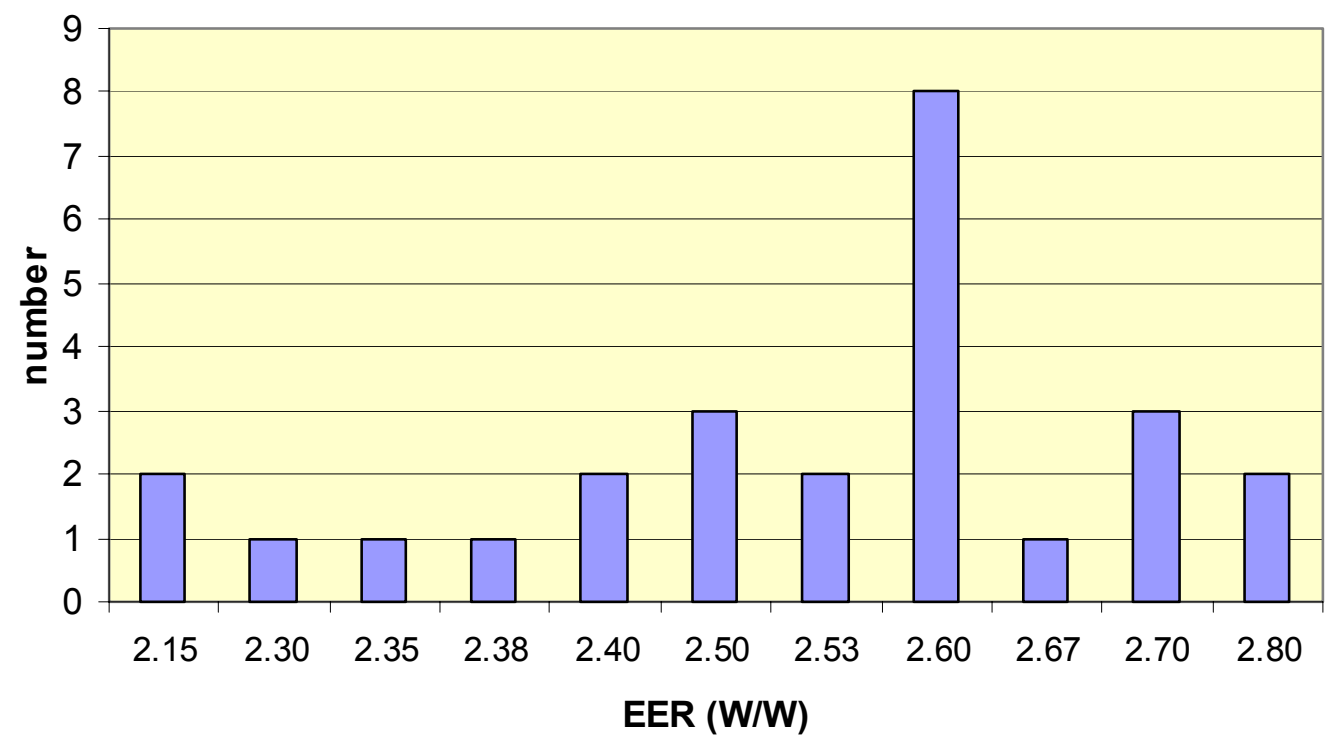

\subsection{Air Conditioner Annual Operating Hours}

No known research has been conducted to determine the energy consumption of room air conditioners in Chinese households. As a result, in 1998, a U.S. Environmental Protection Agency (EPA)-sponsored air conditioner metering study of 150 households in Beijing, Shanghai and Guangzhou collected detailed information about the usage of air conditioners in these cities of the course of one year. Figure 2.8 provides a map of China highlighting the cities of Beijing, Shanghai, and Guangzhou. In the Beijing area, the summer of 1998 was not as hot as usual, and usage of air conditioning was fairly low. According to our analysis of the metering data, the average usage time for air conditioners in Beijing was about 140 hours, far lower than that recorded in Shanghai and Guangzhou ${ }^{1}$. In Shanghai, average household usage was about 290 hours, and 395 hours in Guangzhou, a full 182\% higher than in Beijing. Considered together, the average usage in the three cities totaled 277 hours.

In China, regional climate variations are quite large, and air conditioner usage varies significantly from region to region. Moreover, in the current stage of air conditioner market development, many "residential" air conditioners are installed and used in office buildings and other non-residential situations, where usage patterns are unclear. As a result, it is difficult to derive a single figure to represent average national usage, but for the sake of the current engineering study, the three-city average figure of 277 hours was used.

In the EU, where split systems account for about $69 \%$ of sales, average usage is considerably higher, and also varies by climate zone. The Union average for residential usage is 519 hours,

\footnotetext{
${ }^{1}$ In this study, air conditioner usage for cooling was defined as the period between April 1 and November 1 for Beijing and Shanghai, and between April 1 and December 1 for Guangzhou.
} 
varying between 147 hours in Vienna, in cooler central Europe, to 1400 hours in parts of Spain. (Adnot 2000) As the average income of China's residents grows, usage may be expected to increase as well.

Figures 2.9 to 2.12 provide details on the distribution of usage hours for air conditioners in the three cities.

Figure 2.8 Map of China highlighting Beijing, Shanghai, and Guangzhou

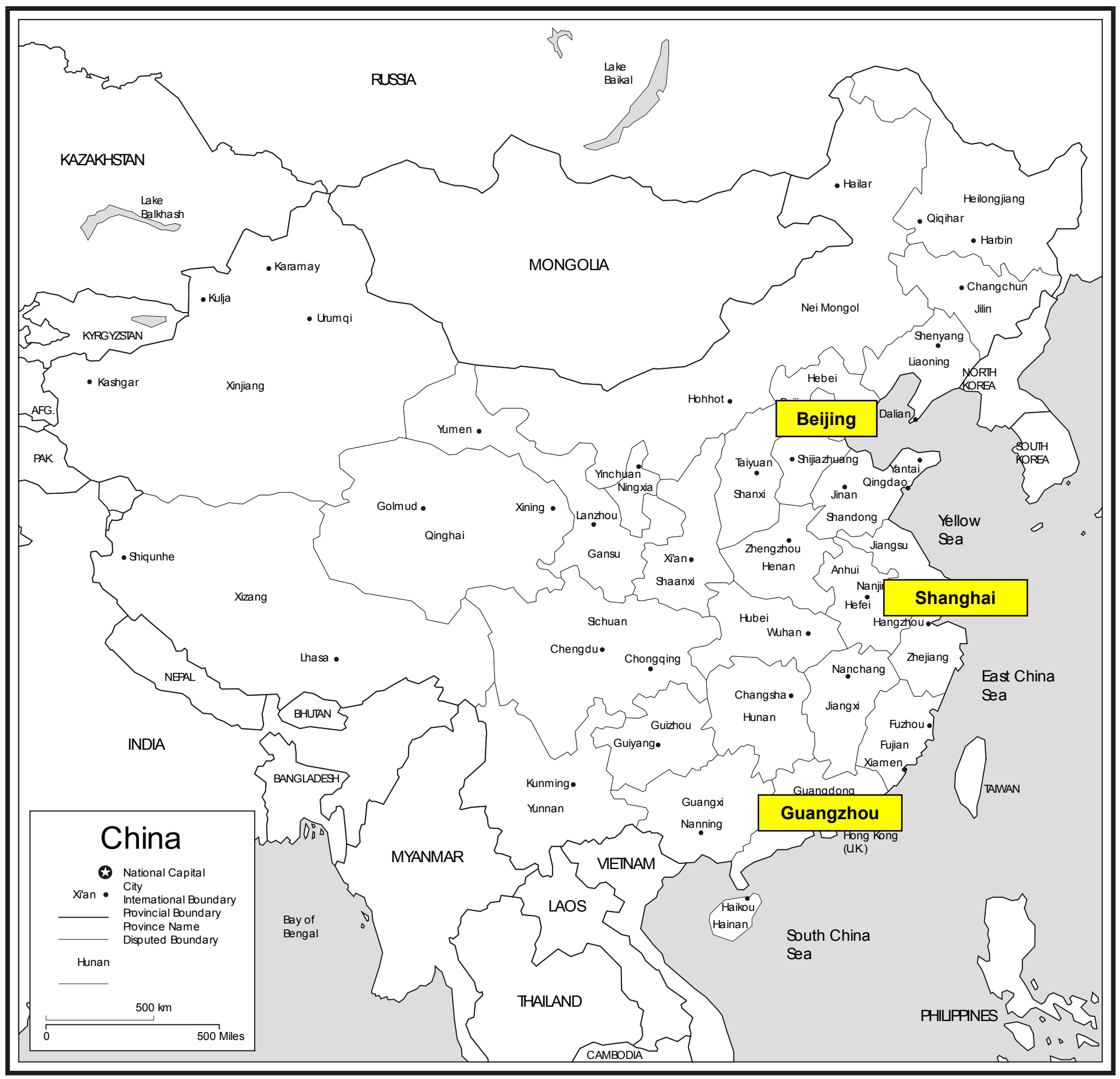


Figure 2.9 Air Conditioner Usage in Beijing

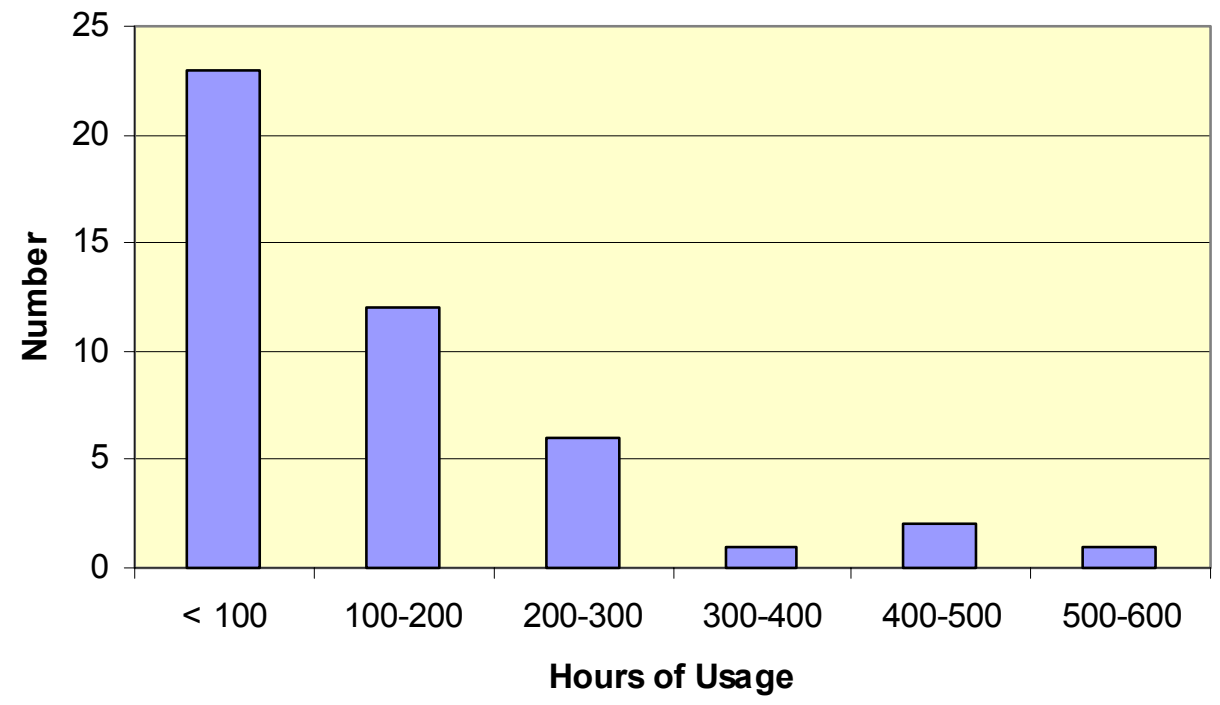

Figure 2.10 Air Conditioner Usage in Shanghai

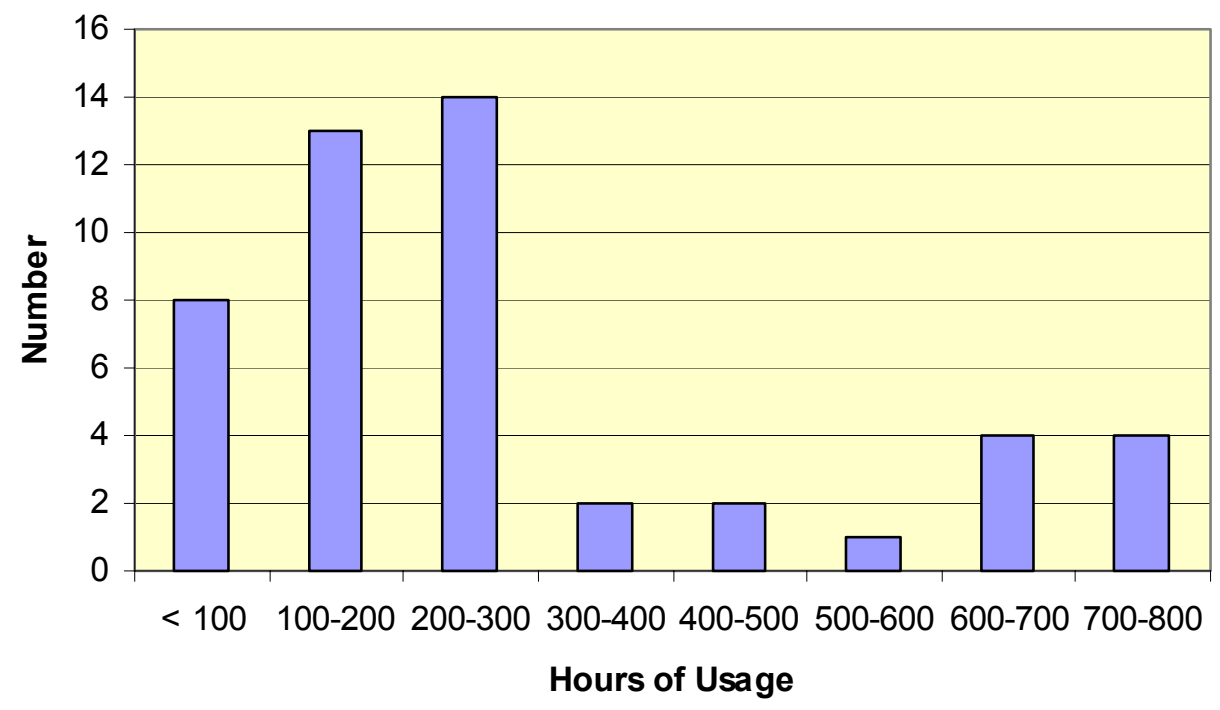


Figure 2.11 Air Conditioner Usage in Guangzhou

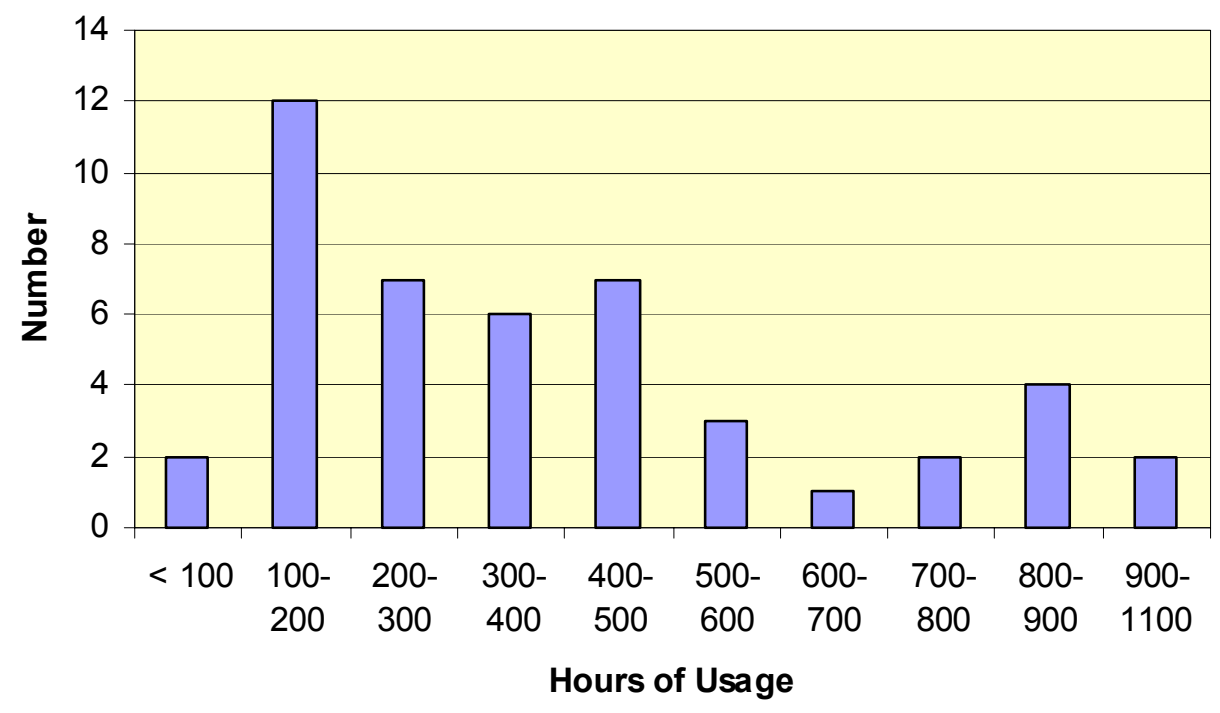

Figure 2.12 Combined Air Conditioner Usage in Three Cities

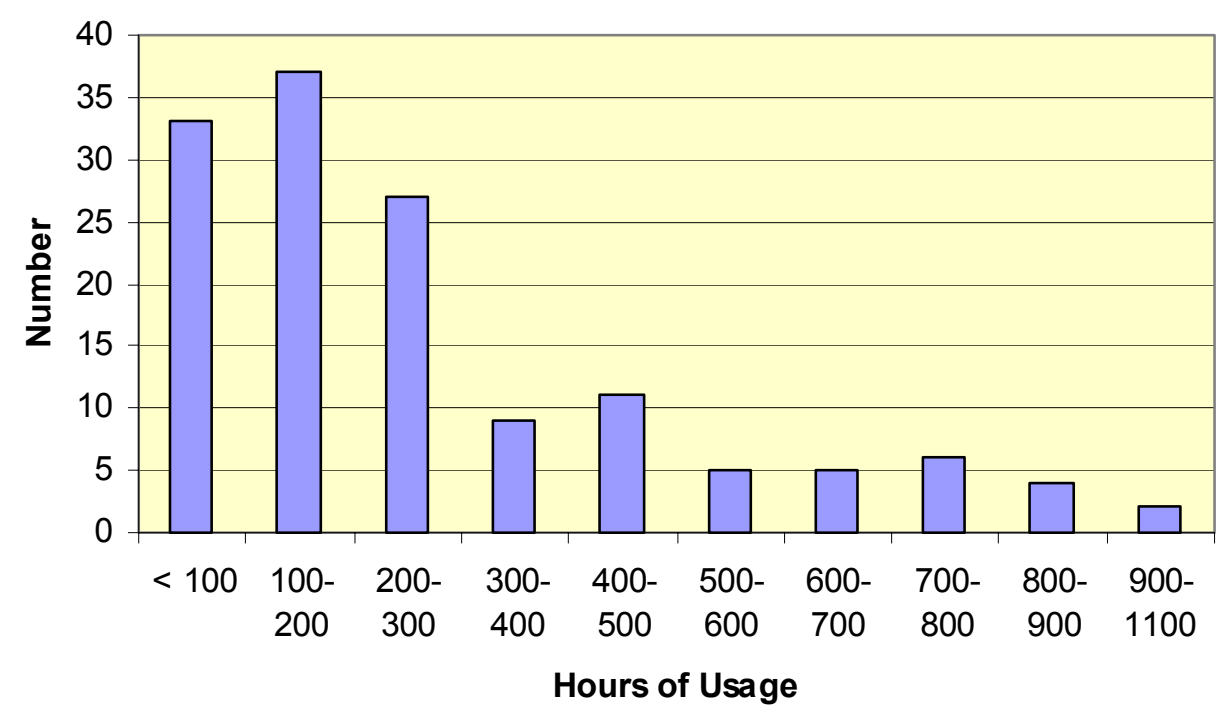




\subsection{Engineering/Economic Analysis}

\subsection{Introduction}

The engineering and economic analyses used in determining energy efficiency standards examine the costs, technical feasibility, and economic feasibility of increasing energy efficiency. Included is a comprehensive assessment of product costs and impacts on energy consumption. The main components of the analysis include the following:

- Engineering Analysis which assesses the cost and efficiency impacts of technical options for increasing product efficiency,

- Life-Cycle Cost Analysis,

- National Energy Savings and National Economic Impacts, and

- Environmental Impacts (reduction in Carbon emissions from electric power plants)

Each of the above four components of the standards analysis are discussed in detail in the following sections.

\subsection{Engineering Analysis}

The primary purpose of the Engineering Analysis is to determine the cost and efficiency impacts of technical (i.e., design) options for increasing product efficiency. The procedure for conducting the Engineering Analysis is as follows:

1) Develop product classes: In the Engineering Analysis, products on the market are classified by capacity or some other performance-related feature which impacts energy-efficiency. Performance-related features typically account for product amenities which offer consumers additional function or utility. The overall rationale of product classification is to allow different energy efficiencies for products that have different performance and applications. A thorough engineering analysis is then applied for each product class.

2) Choose baseline unit: The baseline unit is the starting point of the analysis. The baseline unit serves as the basis from which design options for efficiency enhancement are analyzed. For products or product classes where minimum energy efficiency standards already exist, the efficiency of the baseline unit is typically set at the current minimum level. Otherwise, the efficiency of the baseline unit is typically set at either the average or the minimum efficiency level of available products within the product class.

3) Choose design options to improve product efficiency: For each product class, a variety of design options are considered which can improve the energy efficiency of the product. The choice of design options typically consider existing energy saving options currently utilized by the industry and prototypical technologies under development which would be available 
to the industry at the time a new energy efficiency standard becomes effective. The incremental impact on energy efficiency is determined for each design option.

4) Determine manufacturer cost estimates for each design option or combination of options: For each of the design options which have been deemed technically feasible, manufacturer cost estimates are determined. Cost estimates are typically based on information provided by manufacturers or component suppliers to the industry. In some cases, comparable cost studies from similar industries or other countries are used if cost data cannot be provided by the industry.

5) Combine design options, and calculate overall efficiency improvement: To raise efficiency, the baseline unit is modified to include design changes which have been identified as being technically feasible. Each design option is considered independently first, and then in combination with others if appropriate. For each design option or combination of design options, the efficiency and energy use impacts are either obtained through testing or calculated through appropriate engineering computer simulation models.

6) Establish cost-efficiency curves: After the manufacturer cost and efficiency impacts of the design options are determined, the information is combined and graphically represented as a cost-efficiency curve which depicts the relationship between increased manufacturer cost and increased efficiency. The cost-efficiency relationship is the primary output from the Engineering Analysis.

\subsubsection{Product Classes}

As presented earlier in Section 2.2, Product Types, 14 types of air conditioners have been defined based on the classification methodology in GB/T7725. The classes are presented again below (Table 3.1).

Table 3.1 Air Conditioner Product Classes

\begin{tabular}{|c|c|c|c|c|}
\hline & \multicolumn{2}{|c|}{ Single-package } & \multicolumn{2}{|c|}{ Split } \\
\hline & Cooling-only & Heat-pump & Cooling-only & Heat-pump \\
\hline \multirow{4}{*}{$\begin{array}{c}\text { Rated Cooling } \\
\text { Capacity, C (W) }\end{array}$} & \multicolumn{2}{|c|}{$\mathrm{C} \leq 2500$} & \multicolumn{2}{|c|}{$\mathrm{C} \leq 2500$} \\
\hline & \multicolumn{2}{|c|}{$2500<\mathrm{C}<4500$} & \multicolumn{2}{|c|}{$2500<\mathrm{C}<4500$} \\
\hline & \multicolumn{2}{|c|}{$\mathrm{C} \geq 4500$} & \multicolumn{2}{|c|}{$4500 \leq \mathrm{C}<7100$} \\
\hline & \multicolumn{2}{|c|}{-} & \multicolumn{2}{|c|}{$\mathrm{C} \geq 7100$} \\
\hline
\end{tabular}

In Table 3.1, "single-package" most commonly refers to window air conditioners, and "split" commonly refers to wall-mounted splits and cabinet splits; cabinet splits for the most part are concentrated in the "C $>7100$ " capacity category.

Air conditioners with variable-speed motors will not be considered in this revision because of the lack of an internationally recognized testing method. In addition, since the use of variable-speed motors allows for more efficient operation of the air conditioner it is not necessary at the moment to designate a minimum energy performance standard for this type of air conditioner. 


\subsubsection{Baseline Units}

Data was collected from Chinese air conditioner manufacturers for purposes of identifying baseline units for each of the product classes listed in Table 3.1. Data was provided for only three of the 14 classes listed in Table 3.1; single-package air conditioners (cooling-only) with cooling capacities less than 2500 Watts, split air conditioners (heat pump-type) with cooling capacities between 2500 and 4500 Watts, and split air conditioners (heat pump-type) with cooling capacities greater than 7100 Watts. As described earlier, the selected baseline units should have efficiencies which are equal to or close to the existing minimum efficiency standards for the classes they are representing. But due to the lack of quality data (i.e., data which described the physical characteristics of the unit as well as its performance under standard rating conditions), two of the three baseline units had efficiencies that far exceeded the existing minimum standards. The physical characteristics of the three selected baseline units are provided in Table 3.2.

Table 3.2 Characteristics of three baseline units

\begin{tabular}{|c|c|c|c|c|c|}
\hline & & & Package & Split (singl & aporator) \\
\hline Prod & Ict Class & & $\begin{array}{c}\text { Cooling-only } \\
\text { C } \leq 2500\end{array}$ & $\begin{array}{c}\text { Heat pump } \\
2500<C<4500\end{array}$ & $\begin{array}{c}\text { Heat pump } \\
\mathrm{C} \geq 7100\end{array}$ \\
\hline Rate & Cooling Capacity & $\mathrm{C}(\mathrm{W})$ & 1700 & 3500 & 12000 \\
\hline Rate & EER $(\mathrm{W} / \mathrm{W})$ & & 2.6 & 2.7 & 2.25 \\
\hline Refr & serant & & $\mathrm{R}-22$ & $\mathrm{R}-22$ & $\mathrm{R}-22$ \\
\hline Flon & Control Device & & Capillary tube & Capillary tube & Capillary tube \\
\hline & & Face area $\left(\mathrm{m}^{2}\right)$ & 0.075 & 0.1732 & 0.4284 \\
\hline Eva! & orator & Fin type & Slit & Slit & Louvered \\
\hline & & Tube type & Smooth & Grooved & Grooved \\
\hline & & Face area $\left(\mathrm{m}^{2}\right)$ & 0.14 & 0.42 & 1.00 \\
\hline Conc & enser & Fin type & Slit & Wavy & Wavy \\
\hline & & Tube type & Smooth & Smooth & Smooth \\
\hline & & Type & Rotary & Rotary & Rotary \\
\hline $\mathrm{Com}$ & 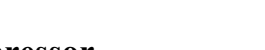 & Cooling capacity (W) & 2500 & 3990 & 16614 \\
\hline Com & ressor & Displacement $\left(\mathrm{cm}^{3}\right)$ & 12.5 & 23.2 & 125.2 \\
\hline & & Efficiency (W/W) & 3.0 & 3.0 & 2.8 \\
\hline & & Air volume $\left(\mathrm{m} / \mathrm{h}^{3}\right)$ & 900 & 478 & 1450 \\
\hline & Evaporator-side & Efficiency & $29 \%$ & $29 \%$ & $32 \%$ \\
\hline & & Type & Asynchronous & PSC & PSC \\
\hline Fan & & Air volume $\left(\mathrm{m} / \mathrm{h}^{3}\right)$ & 400 & 1500 & 2016 \\
\hline & Condenser-side & Efficiency & $29 \%$ & $30 \%$ & $29 \%$ \\
\hline & & Type & Asynchronous & PSC & PSC \\
\hline
\end{tabular}

\subsubsection{Design Options}

To understand how technological changes, other wise known as design options, can improve system performance, the basic operation of an air conditioner and heat pump is described.

An air conditioner provides conditioned air by drawing warm air from the indoor space and blowing it through the evaporator (indoor heat exchanger coil). In passing through the evaporator, the air gives up its heat content (both sensible and latent) to the refrigerant. The conditioned air is then delivered back to the space by the indoor fan or blower. The compressor takes the va- 
porized refrigerant coming out of the evaporator and raises it to a temperature exceeding that of the outside air. The refrigerant passes on to the condenser (outside heat exchanger coil) where the condenser fan blows outside air over it. The refrigerant gives its heat up to the cooler outside air and condenses. The liquid refrigerant is taken by the flow control device and its pressure and temperature are reduced. The refrigerant re-enters the evaporator where the refrigeration cycle is repeated.

A heat pump utilizes the same components as an air conditioner to provide space-heating in addition to space-cooling. Space-cooling is provided in the same fashion as described above for air conditioners. To provide space-heating a reversing valve is utilized to reverse the flow of refrigerant. Two flow control devices, one for the cooling mode and another for the heating mode, are also used. In providing space heat, the outdoor coil becomes the evaporator and the indoor coil acts as the condenser. In the heating mode, the outdoor coil (evaporator) is operated at an outdoor ambient temperature low enough so that heat can flow from the cold outdoor air into the even colder refrigerant.

There are several design options available to improve the performance and efficiency of air conditioners. Table 3.3 summarizes the design options which have been identified for improving system efficiency.

Table 3.3 Design Options for Air Conditioners

\begin{tabular}{|l|l|}
\hline \multirow{4}{*}{$\begin{array}{l}\text { Component } \\
\text { Area }\end{array}$} & Design Options \\
\cline { 2 - 2 } & Increase Frontal Heat Exchanger Area \\
\cline { 2 - 2 } $\begin{array}{l}\text { Improve Heat Transfer Per- } \\
\text { formance }\end{array}$ & Increase Tube Rows \\
\cline { 2 - 2 } & Increase Fin Density \\
\cline { 2 - 2 } Increase Compressor & Idd Subcooler to Outdoor Heat Exchanger \\
\cline { 2 - 2 } Efficiency & Improve Fin Design \\
\cline { 2 - 2 } & Hydrophilic-Film Coating on Fins \\
\cline { 2 - 2 } Increase Fan and Fan-Motor & Spray Condensate on to Outdoor Heat Exchanger \\
\hline Efficiency & High-Efficiency Rotary Compressor \\
\hline Control system & High-Efficiency Scroll Compressor \\
\cline { 2 - 2 } & Variable-Speed Compressor \\
\hline Flow control device & High-Efficiency Permanent Split Capacitor (PSC) Motor \\
\hline Refrigerant & Tlectronically Commutated Motor (ECM) \\
\hline
\end{tabular}

Increase Heat Transfer Surface Area and Improve Heat Transfer Performance. Almost all heat exchanger coils are made of aluminum fins and copper refrigerant tubing. As listed in Table 3.3, there are several methods in which to improve the performance of the coils.

Increase Frontal Coil Area and Increase Tube Rows. Increasing the total evaporator or condenser coil surface area by adding tube rows or increasing the frontal area is limited by the cabinet in which the unit is constructed. A larger cabinet is typically required to accommodate a larger face area or more tube rows as the heat exchanger coils usually have been maximized for the greatest face area and depth. Units with the highest efficiency have relatively large coils for 
their capacity size. Manufacturers typically produce a set number of standard cabinet sizes for an entire model line. The most efficient units tend to be the smallest capacity model to be installed in a particular cabinet size. Thus, their high efficiency is due in large part to their higher coil size-to-capacity ratio.

Increase Fin Density. Increasing the fin density is another option for increasing the total surface area. Manufacturers typically attempt to maximize the fin density in most of their heat exchanger designs. Any further increases might lead to premature coil degradation as dirt particles could more easily lodge between the tightly packed fins. In addition, if fin densities are too high, the increased air-side pressure drop and the resulting increase in fan motor power consumption can negate any increase in heat transfer performance.

Add Subcooler to Condenser Coil. This design option is reserved for single-package (i.e., window-type) air conditioning units, but few single-package designs utilize subcoolers as most manufacturers attempt to achieve the desired amount of subcooling through redesign of the condenser before trying to incorporate a subcooler. Typically, subcoolers are added between the condenser outlet and the flow control device (e.g., capillary tube) inlet and are submerged near the condenser in the condensate produced by the evaporator. The effect of adding a subcooler is to increase the size of the condenser coil as it further cools the refrigerant coming out of the condenser.

Improve Tube Design. Grooved or rifled tubing has its interior surface augmented with straight or spiral grooves. The added surface area created by the grooves improves the refrigerant-side heat transfer coefficient over that of smooth refrigerant tubes. There are several grooved and rifled tubes designs which have varying levels of efficiency improvement. Over the past few years the Chinese air-conditioning industry has quickly adopted the use of grooved and rifled refrigerant tubing with many models now available on the market that utilize this design enhancement.

Improve Fin Design. Improving fin design is achieved through the use of corrugated, louvered, or slit-type fin surfaces. The corrugated fin surface consists of a wavy fin pattern. The louvered fin surface has an appearance similar to that of louvered interior shades for windows. The slittype fin surface usually consists of small strips raised from the base plate fin surface. All of the above fin surfaces increase the air turbulence over the coil and, thus, increase the air-side heat transfer coefficient. Slit-type and louvered fins yield better efficiency results than corrugated fins. Most manufacturers develop a unique fin design to achieve a desired heat transfer improvement. As with grooved and rifled refrigerant tubing, the Chinese air-conditioning industry has quickly adopted the use of enhanced fin surfaces into their equipment designs.

Hydrophilic-Film Coating on Fins. Fins with hydrophilic coatings have an affinity for water causing condensed water to film the fin surface in a thin layer. The strong affinity for water results in less retention of bridge-shaped water drops between fin surfaces. According to research, this in turn causes the water drops to fall off the fin surface quickly resulting in reduced air-side pressure drops and increased airflow rates across the heat exchanger (Mimakim 1987). Under indoor dehumidifying conditions, hydrophilic-type fin surfaces have been shown to reduce air-side pressure drop. Therefore, cooling capacity is improved as compared to air-conditioning systems using untreated fins. reduction in air-side pressure drop can also be achieved with hydrophilic- 
type fins under outdoor defrosting conditions. Heating capacity can be improved and defrosting times can be shortened as compared to heat pump systems using untreated fins. Some Chinese manufacturers are using hydrophilic-film coatings in their air-conditioning systems.

Spraying Condensate onto Condenser Coil. As with subcoolers, this design option is reserved for single-package (i.e., window-type) air conditioning units and is commonly used in these units. This design consists of collecting the condensate dripping off the evaporator coil, diverting it to a shallow reservoir underneath the condenser coil, and then utilizing what is termed a slinger ring which is attached to the tips of the condenser fan to spray the condensate onto the condenser coil. The spray improves the air-side heat transfer coefficient of the condenser.

Improve Compressor Efficiency. Most Chinese air conditioner and heat pump manufacturers purchase their compressors from compressor manufacturers rather than manufacture their own. The most commonly used types are rotary and scroll compressors. Rotary compressors tend to be used in small- to mid-capacity systems while scroll compressors tend to be used in mid- to large-capacity units. Rotary compressors are almost exclusively used in single-package (i.e., window-type) units as cabinet height constraints usually prohibit the use of tall scroll compressors. Since the cabinet constraints in split systems are not as severe as in single-package systems, scroll compressors are commonly utilized in split system designs.

System efficiency can be improved by simply utilizing more efficient compressors. Compressor efficiency is improved through the use of high-efficiency motors, high-grade materials in the pumping mechanism, and advanced production methods and equipment. The most efficient compressors available to the Chinese air-conditioning industry are rated at efficiencies of 3.1 to 3.2 EER, which are equal to that of compressors available in the United States market.

Variable-Speed Compressors. Variable-speed compressors are also available to Chinese manufacturers. The advantages of variable-speed compressors are: 1) they can match changing loads very well, better than switch control mechanisms, 2) in low-speed operation their noise level is low, 3) they reduce indoor temperature fluctuations, 4) they improve seasonal energy efficiency performance, and 5) they improve system dehumidification. However, as mentioned previously, current test procedures only measure equipment performance under static conditions and are, thus, unable to capture the seasonal efficiency improvements due to variable-speed compressors.

Currently, variable-speed compressors account for only 3\% of China's air conditioner market and nearly are all imported, mostly from Japan. The price premium of these air conditioners - at about $30 \%$ - has limited their market expansion, especially in view of the extremely pricecompetitive market situation for other models. (CECA 99)

The control of variable-speed compressors is accomplished through the use of either: 1) electronic adjustable speed drives (ASD) at an induction motor or 2) electronically commutated motors (ECM). In the case of ASD induction motors, because they are compact and do not have to be mechanically coupled to the motor, they can be easily retrofitted to fractional size horsepower motors. Inverter-based ASDs are the most common systems for variable-speed induction motors. In these systems, the input AC power supply is first converted to DC by using a solid-state rectifier. The DC signal is than taken by the inverter to supply a variable-frequency, variable- 
voltage $\mathrm{AC}$ waveform to the motor. The waveform is released in short steps or pulses of power. The speed of the motor will then change in proportion to the frequency. ASDs have been demonstrated to perform well with both rotary and scroll compressors. The heat pump market in Japan is now dominated by split systems equipped with variable-speed rotary compressors, although research has indicated that variable-speed scroll compressors can also be effectively used (Takebayashi 1994).

Variable-speed systems that were once offered in the U.S. have incorporated ECM driven reciprocating-type variable-speed compressors. The ECM, also known as a brushless permanent magnet motor, is a direct current (DC) motor that is even more efficient than an induction motor. ECMs are extremely well suited for variable-speed applications as their efficiency degrades only slightly at part-load conditions. An electronically controlled converter-based system is used to control the ECM speed.

Whether using inverter-based ASDs coupled with induction motors or ECMs, variable-speed compressors perform significantly better at part-load conditions than single-speed systems. Based on seasonal performance, research has demonstrated that energy savings from $15 \%$ to 40\% are attainable using variable-speed compressors (Bahel 1989; Henderson 1990; Hori 1985). Although significantly more efficient than single-speed systems at part-load conditions, variablespeed systems generally perform no better than single-speed systems at full-load conditions. Because of the parasitic losses associated with the electronics required to operate variable-speed compressors, variable-speed systems may actually draw more power than single-speed systems at full-load conditions. Thus, although they are able to save more energy than single-speed systems, variable-speed systems may exacerbate peak power concerns for electric utilities.

As air-conditioning becomes more prevalent in China in the future, and with it variable-speed systems, the benefits of variable-speed compressors must be weighed against their possible adverse impacts at peak power conditions.

Improve Fan and Fan Motor Efficiency. Air delivery efficiency can be improved most easily by improving the efficiency of the fan motors. Several air conditioner and heat pump models on the Chinese market already use permanent split capacitor (PSC) induction fan motors. PSC motors are a vast improvement over low efficiency shaded pole induction motors. The electronically commutated (ECM) is even more efficient than the PSC motor. As stated earlier, ECMs are also extremely well suited for variable-speed applications as their efficiency degrades only slightly at part-load conditions.

Because improvements in fan efficiency are more difficult to implement for air conditioner manufacturers than motor improvements (i.e., a redesign of the fan is required as opposed to replacing the motor with a more efficient type), fan efficiency improvements were not considered in this analysis.

Thermostatic and Electronic Expansion Valves. The capillary tube and the short tube orifice are pressure-reducing devices that connect the outlet of the condenser to the inlet of the evaporator. They are designed to provide optimum energy characteristics at one design point. If sized properly, they can compensate automatically for load and system variations and provide accept- 
able performance over a wide range of operating conditions. The capillary tube or the short tube orifice is the most typical flow control device utilized by the Chinese air-conditioning industry.

Thermostatic expansion valves (TXV) are another type of flow control device. They regulate the flow of liquid refrigerant entering the evaporator in response to the superheat of the refrigerant leaving it. TXVs can adapt better to changes in operating conditions such as those due to the variation in ambient temperatures, which affect the condensing temperature. As a result, TXVs can improve equipment seasonal energy efficiency performance.

Electronic expansion valves are similar to TXVs but, since they can be controlled by electronic circuits, they give the additional flexibility to consider control schemes that are impossible for conventional TXVs (ASHRAE 1998). As with TXVs, electronic valves can use the superheat control method to regulate refrigerant flow. Other methods, such as controlling compressor discharge temperature, can also be used. When incorporated into air-conditioning systems using inverter-driven variable-speed compressors, electronic expansion valves can improve seasonal energy efficiency beyond that of systems using conventional TXVs.

As with variable-speed compressors, the main benefit of thermostatic and electronic expansion valves are to improve efficiency on a seasonal basis. Because current test procedures to do not measure seasonal performance, there is no motivation for manufacturers to utilize this technology.

Thermostatic Cyclic Controls. Remote thermostatic cyclic controls more accurately monitor room temperature than either remote or built-in thermostats. Research work has been investigating the use of a fuzzy logic controllers for space-conditioning applications. These controller types have been shown to improve the performance of space-conditioning systems over that of conventional controllers. Although a remote-based fuzzy logic thermostat may offer comfort improvements, efficiency gains would most likely require that it be coupled with an improved air flow discharge and distribution system so as to better mix the room air. As a result, thermostatic controls could only yield efficiency gains on a seasonal basis.

Alternative Refrigerants. R-22 is currently used in all air-conditioning and heat pump equipment. But because it is a hydrochloroflurocarbon (HCFC) and demonstrates ozone depletion potential (ODP), its production and use have been targeted for elimination. Two alternatives have shown promise; 1) R-407C, a ternary blend of HFC-32/HFC-125/HFC-134a with composition of $23 / 25 / 52 \%$ by weight and 2) R-410A, an azeotrope of HFC-32/HFC-125 with composition of $50 / 50 \%$ by weight. But both have demonstrated shortcomings when compared to R-22. Systems with R-407C yield efficiencies that are approximately 5\% less than those charged with R-22, while R-410A exhibits significantly higher compressor discharge pressures. According to the development plan of China's Association of Light Industries, equipment utilizing new refrigerants will be in production by 2020 . Due to the uncertainty regarding the near term use of alternative refrigerants, only R-22 is currently considered a viable refrigerant. 


\subsubsection{Manufacturer Costs}

Chinese air conditioner manufacturers were surveyed as to the cost impacts of incorporating several of the design options described above. With the exception of variable-speed compressors, cost data were supplied only for design options which improved efficiency on a steady-state rather than a seasonal basis. Table 3.4 summarizes the design option cost data.

Because Chinese manufacturers did not provide cost data for improvements in rotary compressor efficiency, these data were derived from costs pertinent to the United States single-package (i.e., window-type) air conditioner market (US DOE 1997). Since more efficient compressors are commonly employed by manufacturers for improving system performance, for analysis purposes, it was important to have an estimate of how they impact manufacturer costs.

Table 3.4 Design Option Manufacturer Costs

\begin{tabular}{|c|c|c|}
\hline Component & Design Option & Manufacturer Cost \\
\hline \multirow{5}{*}{ Fin } & Flat aluminum fin & 26 yuan per kg \\
\hline & Hydrophilic aluminum fin & 36 yuan per $\mathrm{kg}$ \\
\hline & Wavy fin & $35 \%$ increase over flat fin \\
\hline & Louvered fin & $45 \%$ increase over flat fin \\
\hline & Slit fin & $55 \%$ increase over flat fin \\
\hline \multirow{3}{*}{$\begin{array}{l}\text { Refrigerant } \\
\text { tube }\end{array}$} & Smooth tube & 28 yuan per kg \\
\hline & Standard grooved tube & 15 yuan per lineal meter \\
\hline & High-efficiency grooved tube & 20 yuan per lineal meter \\
\hline \multirow{3}{*}{ Fan Motor } & $\begin{array}{l}10 \% \text { more efficient than standard PSC } \\
\text { motor }\end{array}$ & 20 yuan over cost of standard PSC motor \\
\hline & $\begin{array}{l}20 \% \text { more efficient than standard PSC } \\
\text { motor }\end{array}$ & 40 yuan over cost of standard PSC motor \\
\hline & ECM fan motor & 400 yuan \\
\hline \multirow{4}{*}{ Compressor } & Rotary Compressor $^{1}: 2.10$ to 3.10 EER & Yuan per 0.1 EER incr. $=8.1+(4.0 \cdot$ cooling cap in $\mathrm{kW})$ \\
\hline & Rotary Compressor ${ }^{1}: 3.10$ to 3.24 EER & Yuan per 0.1 EER incr. $=23+(4.5 \cdot$ cooling cap in $\mathrm{kW})$ \\
\hline & Scroll Compressor & 400 yuan over cost of rotary compressor \\
\hline & Variable-speed Compressor & 1500 yuan over cost of single-speed rotary \\
\hline
\end{tabular}

${ }^{1}$ Costs derived from compressor data for the U.S. market.

\subsubsection{Cost-Efficiency Analysis}

The cost-efficiency analysis establishes the increased manufacturer cost for producing a more efficient product. A cost-efficiency analysis was conducted only for the baseline unit for the split air conditioner (heat pump-type) product class with cooling capacities between 2500 and 4500 Watts. The other two baseline units as described in Table 3.2 (package systems (cooling-only) with capacities below 2500 Watts and split systems (heat pump-type) with capacities greater than 7100 Watts) did not have the necessary test data for performing simulation model calibrations. The simulation model and its calibration are discussed in the following two sections.

Although the cost-efficiency analysis could only be conducted for split system heat pumps with cooling capacities between 2500 to 4500 Watts, this product class represents a majority of equipment sales in China. As presented earlier in Table 2.2, all split systems (including both cooling-only and heat pump-type) with capacities in the 2500 to 4500 Watt range comprised over 
$43 \%$ of total equipment sales in 1998. Thus, the cost-efficiency analysis conducted for this class is representative for most of the equipment produced in China.

In the cost-efficiency analysis various design options are calibrated on top of the baseline model and their impacts on energy efficiency are calculated. These design options are first considered independent of each other, and then in appropriate combinations. The efficiency of each design option and combination of design options are determined through the use of a computer simulation model.

\subsubsection{Simulation Model}

Simulations were carried out using the Oak Ridge National Laboratory (ORNL) Heat Pump Design Model, Mark V, version 95d (ORNL 1996; Fischer \& Rice 1983; Fischer, Rice \& Jackson 1988). The ORNL Model is a comprehensive program for the simulation of an electrically driven, air-source heat pump. It is a steady-state model that is able to calculate the energy efficiency ratio (EER) of the equipment being modeled at specified ambient conditions. The simulation model is divided into two main parts; the high side and the low side. The high side includes models for the compressor, the condenser, and the expansion device, while the low side contains the evaporator. The model first performs a high-side balance based on calculating a mass flow rate through the flow control device that matches the one determined for the compressor. Once a high-side balance is achieved, a low-side balance is performed in which the evaporator model seeks an air inlet temperature that ensures the previous balance at the high side.

The simulation model is able to predict the steady-state performance of two-speed and variablespeed systems. In addition, the model includes the following capabilities: 1) extended air-side heat exchanger correlations for modulating applications, 2) a refrigerant charge inventory option allowing the user to either specify or determine the required charge, 3) a provision for variableopening flow controls used in modulating heat pumps (e.g. electronic and thermostatic expansion valves), 4) a provision for input selection of refrigerant, and 5) an automated means to conduct parametric performance mapping of selected pairs of independent design variables. The compressor simulation uses the standardized Air-Conditioning and Refrigeration Institute (ARI) tencoefficient format for specifying the performance of the compressor. ${ }^{2}$

It should be noted that although the ORNL model has the capability to model the performance of modulating systems, only single-speed systems were analyzed for this cost-efficiency analysis. It is worthwhile to note that any future analyses can consider the simulation analysis of modulating systems, providing that the necessary data has been collected to analyze these systems.

Because the ORNL model is a comprehensive simulation tool, the input data requirements are extensive. Appendix A provides the completed survey form describing the physical characteristics of the baseline unit that was analyzed. Also in Appendix A is the ORNL Heat Pump Design Model input file for the baseline unit. The baseline unit information was collected from a Chinese air conditioner manufacturer and represents the characteristics of an actual model available on the Chinese market. Refer to Table 3.2 for a brief summary of the basic characteristics of the

\footnotetext{
${ }^{2}$ ARI is the trade association representing most manufacturers in the United States.
} 
baseline unit being modeled for the split system (heat pump-type) product class with capacities between 2500 to 4500 Watts.

\subsubsection{Calibration of Simulation Model}

In order to ensure that the ORNL simulation model produced reliable results, simulation results for the baseline unit were compared to actual manufacturer reported test data as measured according to the Chinese testing procedure for air conditioners (GB/T7725). Appendix A.2 provides the measured performance data for the baseline unit.

For the representative baseline unit, correction factors to adjust the calculated compressor power and refrigerant mass flow rate were used to match the predicted performance of the air conditioner to that indicated by the manufacturer supplied test data. In addition to the above correction factors, the length and the diameter of the capillary tube and the compressor shell heat loss were also adjusted to calibrate the model. Calibrations were conducted on the basis of matching the following primary quantities: 1) EER, 2) cooling capacity, and 3) compressor power. Other secondary quantities (e.g., system refrigerant temperatures) were also considered in the calibrations, although the main objective was to achieve relatively small differences between the measured and simulated results for only the primary quantities.

For only the primary quantities, Table 3.5 presents a comparison between the manufacturers' test data and the data predicted from the simulation. Included in the comparison is the percentage difference between the two sets of values. After making all the necessary corrections and adjustments to the input files, both EER and capacity for were predicted to within $0.6 \%$ of values determined from test measurements. Because the calibrated results are so close to the actual test data for the EER and cooling capacity, the simulation model was entrusted to produce reliable results for design option modifications to the baseline unit.

Table 3.5 Comparison between Test Data and Simulation Results

\begin{tabular}{|l|c|c|c|}
\hline \multirow{2}{*}{ Data Description } & \multicolumn{3}{|c|}{ Baseline Unit: Split Heat Pump-type, } \\
& \multicolumn{3}{|c|}{$\mathbf{2 5 0 0}$ W < Capacity < 4500 W } \\
\cline { 2 - 4 } & Test data & Simulation outputs & Error \\
\hline EER & 2.7 & 2.69 & $-0.6 \%$ \\
\hline Cooling capacity (Watts) & 3460 & 3483 & $0.7 \%$ \\
\hline Compressor power $($ Watts) & 1300 & 1188 & $-8.7 \%$ \\
\hline Subcooling $\left({ }^{\circ} \mathrm{C}\right)$ & 6.5 & 6.6 & $1.7 \%$ \\
\hline Compressor outlet temperature $\left({ }^{\circ} \mathrm{C}\right)$ & 15 & 14.7 & $-2.3 \%$ \\
\hline Compressor inlet temperature $\left({ }^{\circ} \mathrm{C}\right)$ & 85 & 87.3 & $2.8 \%$ \\
\hline Condenser inlet temperature $\left({ }^{\circ} \mathrm{C}\right)$ & 70 & 85.9 & $22.7 \%$ \\
\hline Condenser outlet temperature $\left({ }^{\circ} \mathrm{C}\right)$ & 42 & 43.1 & $2.6 \%$ \\
\hline Evaporator inlet temperature $\left({ }^{\circ} \mathrm{C}\right)$ & 12 & 7.9 & $-34.1 \%$ \\
\hline Evaporator outlet temperature $\left({ }^{\circ} \mathrm{C}\right)$ & 7 & 6.6 & $-5.4 \%$ \\
\hline
\end{tabular}

\subsubsection{Development of New Baseline Unit}

In evaluating the system performance due to different heat exchanger fin and tube designs, data from recent Chinese texts on air conditioner technology were used (Zhou 1997; Kang 1995). 
Table 3.6 summarizes the heat transfer and pressure drop enhancement factors which were utilized to simulate the performance of the different fin and tube designs. The ORNL Heat Pump Design model has specific input variables for these enhancement factors. The enhancement factors are relative to flat fins and smooth tubing (i.e., flat fins and smooth tubing have heat transfer and pressure drop enhancement factors of 1.0).

Table 3.6 Fin and Tube Heat Transfer and Pressure Enhancement Factors

\begin{tabular}{|l|c|c|}
\hline Design & $\begin{array}{c}\text { Heat Transfer } \\
\text { Enhancement Factor }\end{array}$ & $\begin{array}{c}\text { Pressure Drop } \\
\text { Enhancement Factor }\end{array}$ \\
\hline Evaporator Wavy Fin (with smooth tube) & 1.12 & 1.05 \\
\hline Evaporator Slit Fin (with smooth tube) & 1.50 & 1.20 \\
\hline Evaporator Slit Fin (with groove tube) & 1.80 & 1.20 \\
\hline Condenser Wavy Fin (with smooth tube) & 1.11 & 1.05 \\
\hline Condenser Slit Fin (with smooth tube) & 1.44 & 1.25 \\
\hline Condenser Slit Fin (with groove tube) & 1.57 & 1.25 \\
\hline Evaporator Groove Tube & 2.40 & 1.50 \\
\hline Condenser Groove Tube & 2.20 & 1.40 \\
\hline
\end{tabular}

Table 3.7 summarizes which design features were removed to lower the efficiency of the baseline unit. After making the necessary modifications, the new baseline unit has an efficiency of $2.28 \mathrm{~W} / \mathrm{W}$.

Table 3.7 Development of New Baseline Unit

\begin{tabular}{|l|c|c|}
\hline & Capacity & EER \\
\hline Design & $W$ & $W / W$ \\
\hline Original baseline unit design & 3483 & 2.69 \\
\hline Replace 3.0 EER Compressor with 2.7 EER unit & 3478 & 2.43 \\
\hline Replace Groove Tubes with Smooth in Evaporator & 3432 & 2.41 \\
\hline Replace Slit Fins with Wavy in Evaporator - NEW BASELINE & 3102 & 2.27 \\
\hline
\end{tabular}

\subsubsection{Combining Design Options}

As has been noted earlier on several occasions, only design options which improve efficiency on a steady-state rather than a seasonal basis were considered. The primary reason being that the test procedure for rating air conditioners and heat pumps measures only the steady-state performance of the equipment. In addition, with the exception of variable-speed compressors, manufacturers provided cost data only for design options that improve the steady-state efficiency of the equipment.

In analyzing design option modifications to the baseline unit, design options are ordered so that those that are relatively more cost-effective are listed first. For the purpose of ordering design options, cost-effectiveness was determined with simple payback. Design options were placed in order of ascending payback period. The following equation was used to determine the payback period for all design options. 


$$
P B P=\frac{\Delta P C+\triangle I C}{\Delta O C-\triangle M C}
$$

where,

$P B P=$ Payback period (years),

$\triangle P C=$ increase in purchase cost from the baseline unit to the design option, $\triangle I C=$ increase in installation cost from the baseline units to the design option, $\triangle O C=$ decrease in the operating cost from the baseline unit to the design option, and $\triangle M C=$ increase in the maintenance cost from the baseline unit to the design option.

For purposes of this analysis, none of the design options were assumed to impact either the installation or the maintenance cost of the equipment. Thus, the payback period is reduced to the following expression.

$$
P B P=\frac{\triangle P C}{\triangle O C}
$$

The change in the purchase cost is expressed according to the following equation:

$$
\Delta P C=\left(M F C_{\text {design option }}-M F C_{\text {baseline unit }}\right) \cdot M U
$$

where,
$M F C_{\text {design option }}=$
Manufacturer cost of the modified design,
$M F C_{\text {baseline unit }}=$ manufacturer cost of the baseline unit, and
$M U=$ manufacturer to retail price markup.

As provided earlier in Section 2.4, the markup from the manufacturer cost to the retail price is $49 \%$ or 1.49 .

The change in the operating cost is expressed according to the following equation:

where,

$$
\Delta O C=\left(A E C_{\text {baselineunit }}-A E C_{\text {designoption }}\right) \cdot E L E C
$$
$A E C_{\text {design option }}=$
Annual energy consumption of the modified design ( $\mathrm{kWh} / \mathrm{year})$,
$A E C_{\text {baseline unit }}=$ annual energy consumption of the baseline unit ( $\mathrm{kWh} / \mathrm{year})$, and $E L E C=$ electricity price (Yuan/kWh).

The average electricity price for China was assumed to be 0.6 Yuan/kWh (Ogilvy 1999). The annual energy consumption was determined according to the following expression:

$$
A E C=\frac{C A P}{E E R} \cdot \text { Hours }
$$

where,
$C A P=$
Cooling capacity of the air conditioner (Watts),
$E E R=$ energy efficiency ratio (W/W), and
Hours $=$ annual operating hours of an air conditioner. 
As described previously in Section 2.6, the annual operating hours were obtained from survey data for the Chinese cities of Beijing, Shanghai, and Guangzhou in 1998. The average operating hours were determined to be 278 hours.

\subsubsection{Results}

Table 3.8 and Figure 3.1 summarize the cost-efficiency analysis results for the baseline unit. In Table 3.8 the manufacturer cost (both incremental and total), the purchase cost or retail price, the cooling capacity, the efficiency, the annual energy consumption, the annual operating cost, and the payback period are presented. Figure 3.1 graphically shows the relationship between manufacturer cost and increased efficiency. The cost-efficiency analysis shows that an efficiency of 2.92 EER can be achieved by upgrading both the evaporator and condenser with slit fins and grooved refrigerant tubing and increasing the efficiency of the compressor to 3.0 EER.

Table 3.8 Cost-Efficiency Analysis Results for Baseline Unit representing Split System Heat Pump-type, 2500 W < Capacity < 4500 W Product Class

\begin{tabular}{|c|l|c|c|c|c|c|c|c|c|}
\hline & & \multicolumn{2}{|c|}{ Manufacturer Cost } & Retail & & & & & Payback \\
\hline & & Incr. & Total & Price & Capacity & EER & AEC & OC & Period \\
\hline No. & Design Option & Yuan & Yuan & Yuan & Watts & W/W & $\mathrm{kWh} /$ yr & Yuan/yr & Years \\
\hline 0 & New Baseline & 0 & 2983 & 4445 & 3102 & 2.27 & 426 & 256 & - \\
\hline 1 & 0 + Evaporator Slit Fins & 9 & 2992 & 4458 & 3316 & 2.37 & 409 & 245 & 1.28 \\
\hline 2 & 1 + Cond Groove Tube & 27 & 3019 & 4498 & 3388 & 2.53 & 383 & 230 & 2.06 \\
\hline 3 & 2 + Evap Groove Tube & 18 & 3037 & 4525 & 3560 & 2.62 & 370 & 222 & 2.39 \\
\hline 4 & 3 + 3.0 EER Compressor & 60 & 3097 & 4615 & 3556 & 2.89 & 355 & 201 & 3.12 \\
\hline 5 & 4 + Condenser Slit Fins & 15 & 3112 & 4637 & 3572 & 2.92 & 332 & 199 & 3.41 \\
\hline 6 & 5 + 3.16 EER Compressor & 100 & 3212 & 4786 & 3574 & 3.06 & 317 & 190 & 5.19 \\
\hline 7 & 6 + Cond Fan Motor $+10 \%$ & 20 & 3232 & 4816 & 3574 & 3.08 & 314 & 189 & 5.54 \\
\hline 8 & 7 + Evap Fan Motor $+10 \%$ & 20 & 3252 & 4845 & 3577 & 3.09 & 313 & 188 & 5.93 \\
\hline
\end{tabular}

An EER of 2.92, while a 29\% jump from the 2.27 EER minimum in place through 2000 for split system heat-pump type systems, is still significantly lower than comparable EER requirements for Japanese wall-mounted non-ducted split units. According to MITI's 1999 Notification, heat pump and cooling-only split units of 2501 to $3200 \mathrm{~W}$ require a minimum EER of 4.90 and 3,64, respectively, and those of 3201 to $4000 \mathrm{~W}$ require minimums of 3.65 and 3.08 , respectively. This level, however, would appear to be almost in par with current US minimum standards. A direct comparison is not possible, as the US does not have a comparable product class, but using window-mounted air conditioners as a comparison, those in the $2345-4100 \mathrm{~W}$ range in the US are restricted to a minimum EER of 2.87. China's current minimum standard for window air conditioners of less than $4500 \mathrm{~W}$ size is 2.20 EER.

\footnotetext{
${ }^{3}$ Although Japanese equipment are rated as more efficient, it is not entirely clear whether Japanese test procedures are comparable to Chinese test procedures. Thus, the higher ratings for Japanese equipment may be due to credits within the Japanese test procedure that are not available in the Chinese test procedure.
} 
The EER optimum at 2.92, however, is only $8 \%$ higher than what is reported as the current average EER of leading air conditioner models (see discussion, p. 10. On the one hand, this suggests that some manufacturers may already have the technical capacity to reach this higher level of performance, but on the other hand, inaccurate cost data and the $15 \%$ allowable variance in reported design efficiency could result in an overstatement of the average EER of the compiled model data. Still in relative infancy, the air conditioner industry in China remains unconsolidated, with widely varying technical capacity among companies. It is reasonable to believe that leading companies with extensive international research and technical relationships would demonstrate higher average EERs in their production models than the remaining small companies, serving regional and local markets, with an aging technical base. This disparity among technological capacity of the main air conditioner manufacturers is a challenge to the government in determining the final minimum efficiency standard, as they must consider the employment and financial consequences of the ruling.

Figure 3.1 Manufacturer Cost vs. Efficiency for Baseline Unit, Split System, Heat Pump-type, $2500 \mathrm{~W}<$ Capacity $<4500 \mathrm{~W}$

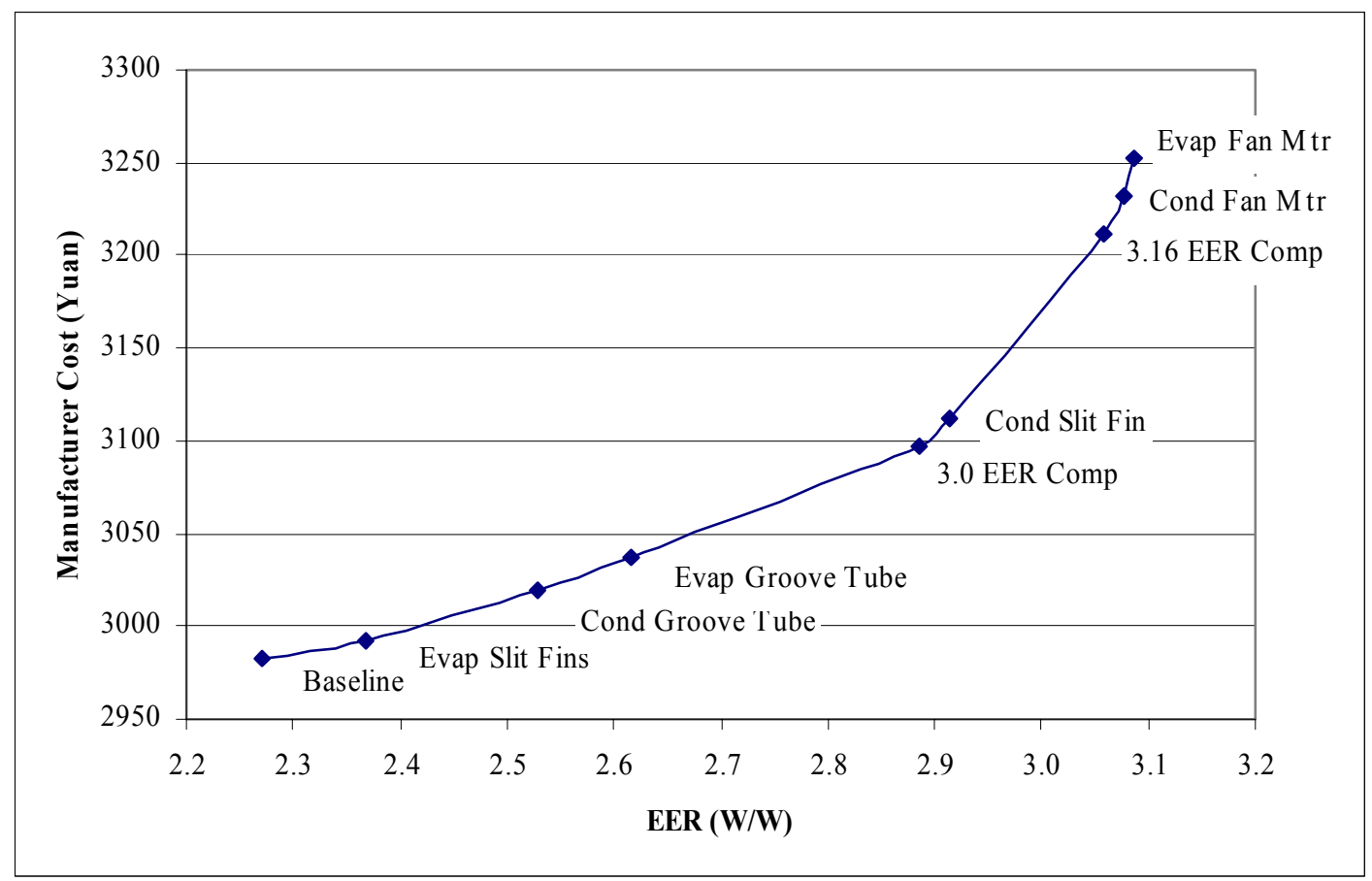

\subsection{Life-Cycle Cost Analysis}

Life-cycle costs (LCC) were determined for all of the design options presented in Table 3.8. The $\mathrm{LCC}$ is another economic factor for establishing the cost-effectiveness of design options that improve the efficiency of a product. The life-cycle cost (LCC) is the sum of the purchase cost $(P C)$ and the present value of operating expenses $(O C)$ discounted over the lifetime $(N)$ of the appliance. If operating expenses are constant over time, the LCC simplifies to: 


$$
L C C=P C+P W F \cdot O C
$$

where the present worth factor is defined as:

$$
\mathrm{PWF}=\sum_{\mathrm{t}=1}^{\mathrm{N}} \frac{1}{(1+\mathrm{r})^{\mathrm{t}}}=\frac{1}{\mathrm{r}}\left[1-\frac{1}{(1+\mathrm{r})^{\mathrm{N}}}\right]
$$

and $r$ is the discount rate.

For the LCC analysis conducted here, $2 \%, 6 \%$, and 15\% discount rates are considered. Analyzing a range of discount rates will show how sensitive the results are to the discount rate value.

\subsubsection{Results}

Table 3.9 shows the LCC results for the design options presented in Table 3.8 for the baseline unit represent the split system product class with capacities between 2500 and 4500 Watts. The LCC results are based on discount rates of $2 \%, 6 \%$, and $15 \%$. Figure 3.2 graphically shows the LCC results based upon a discount rate of $6 \%$ while Figure 3.3 shows graphically how the discount rate impacts the LCC.

Table 3.9 Life-Cycle Cost Analysis Results for Baseline Unit, Split System Heat Pump-type, 2500 W $<$ Capacity $<4500$ W

\begin{tabular}{|c|l|c|c|c|c|c|}
\hline & & & & \multicolumn{3}{|c|}{ Life-Cycle Cost } \\
\hline & & Capacity & EER & $\mathbf{2 \%}$ & $\mathbf{6 \%}$ & $\mathbf{1 5 \%}$ \\
\hline No. & Design Option & Watts & $W / W$ & Yuan & Yuan & Yuan \\
\hline 0 & New Baseline & 3102 & 2.27 & 7247 & 6648 & 5852 \\
\hline 1 & $0+$ Evaporator Slit Fins & 3316 & 2.37 & 7146 & 6572 & 5808 \\
\hline 2 & $1+$ Cond Groove Tube & 3388 & 2.53 & 7015 & 6477 & 5762 \\
\hline 3 & $2+$ Evap Groove Tube & 3560 & 2.62 & 6958 & 6438 & 5747 \\
\hline 4 & $3+3.0$ EER Compressor & 3556 & 2.89 & 6820 & 6349 & 5722 \\
\hline 5 & $4+$ Condenser Slit Fins & 3572 & 2.92 & 6820 & 6354 & 5733 \\
\hline 6 & $5+3.16$ EER Compressor & 3574 & 3.06 & 6868 & 6423 & 5831 \\
\hline 7 & $6+$ Cond Fan Motor $+10 \%$ & 3574 & 3.08 & 6884 & 6442 & 5854 \\
\hline 8 & $7+$ Evap Fan Motor $+10 \%$ & 3577 & 3.09 & 6907 & 6467 & 5881 \\
\hline
\end{tabular}


Figure 3.2 LCC Results for Baseline Unit based on a 6\% Discount Rate, Split System, Heat Pump-type, 2500 W $<$ Capacity $<4500$ W

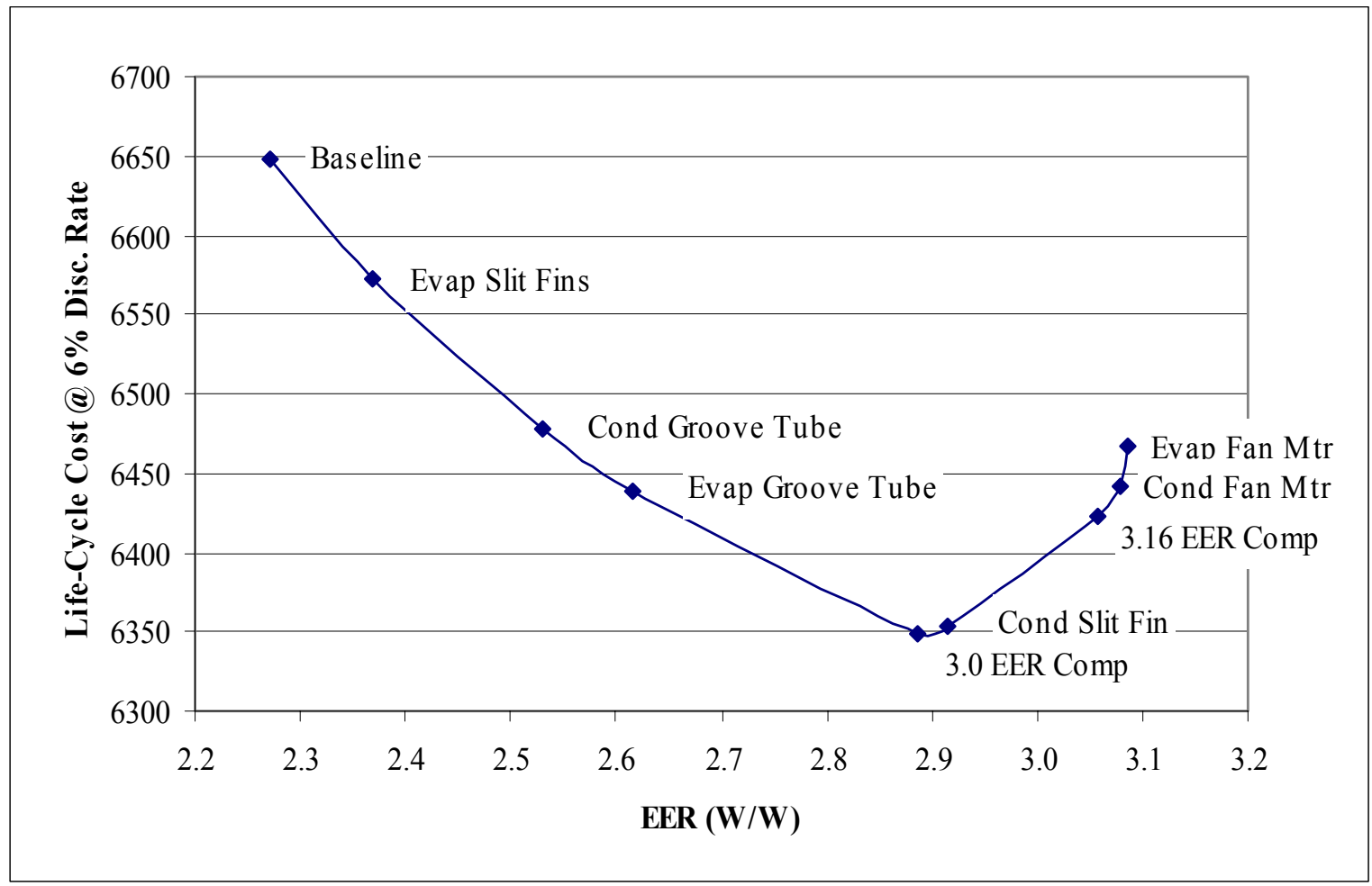

The discount rate impacts the value of future operating costs. As shown in Figure 3.3, the lower the discount rate, the greater the value of the operating costs and, in turn, the greater the overall LCC of the equipment. Since lower discount rates result in greater operating costs, more efficient designs will result in greater operating cost savings and, in turn, greater LCC savings. This effect is shown in Figure 3.3 as the magnitude of the LCC savings increases with lower discount rates. Although the LCC savings are greater at lower discount rates, the minimum LCC still occurs at an efficiency of 2.89 EER regardless of discount rate (note that for a $2 \%$ discount rate, the LCC at 2.92 EER is virtually identical to the LCC at 2.89 EER). The LCC results based on the $2 \%$ and $6 \%$ discount rates reveal that all increased efficiency levels have a lower LCC than the baseline level. With a discount rate of $15 \%$, LCC savings are diminished enough so that the LCC of the most efficient designs (greater than 3.06 EER) are greater than the baseline level. The small variability in the optimum EER among these scenarios is due to the large gap in efficiency levels of the options preceding and following the optimum. 
Figure 3.3 LCC Results for Baseline Unit as a function of Discount Rate, Split System, Heat Pump-type, 2500 W $<$ Capacity $<4500$ W

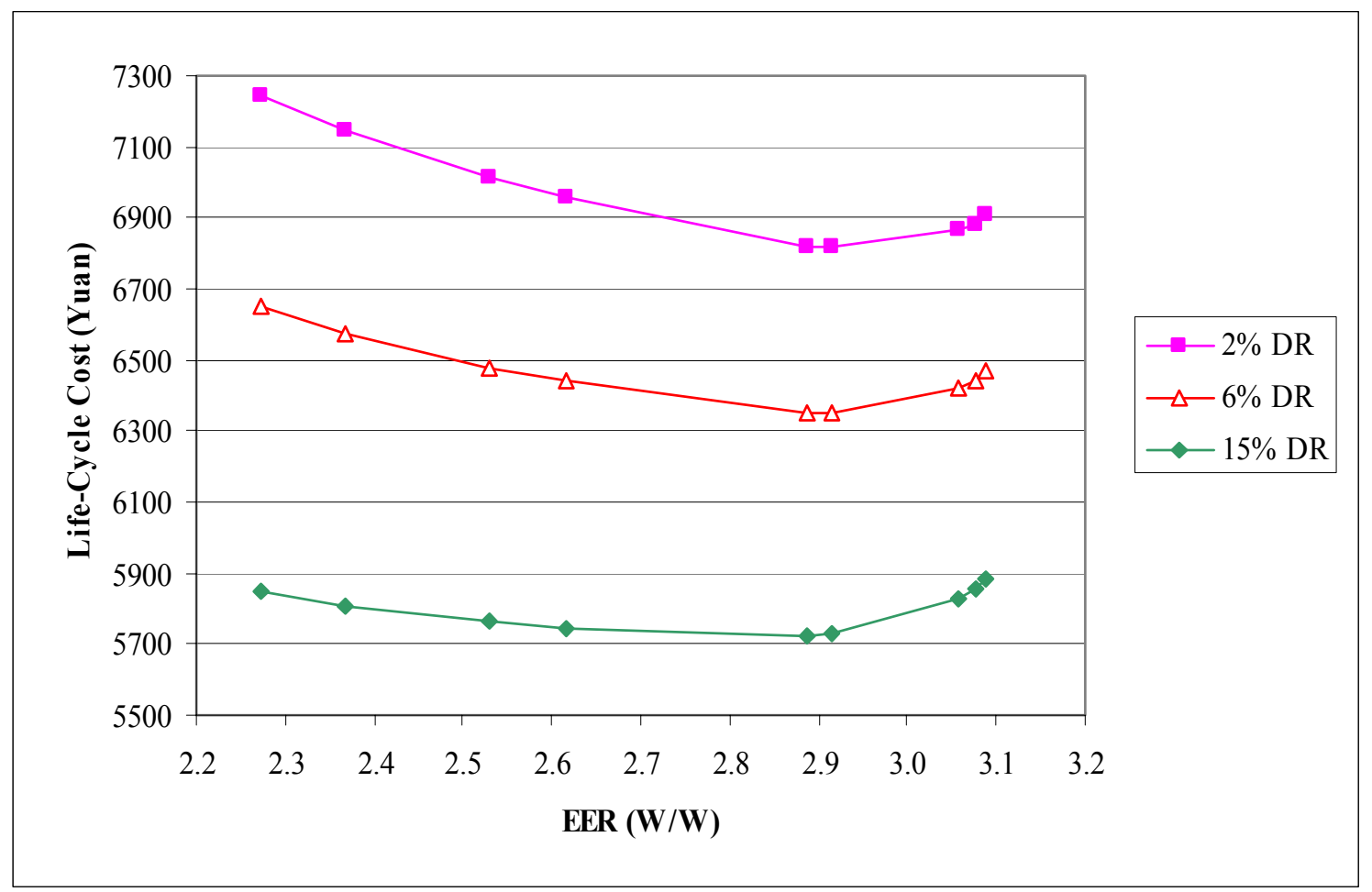

\subsection{National Energy Savings and National Economic Impacts}

This section describes the method for estimating the quantity and value of future national energy savings (NES) due to a likely energy efficiency standard for room air conditioners. The metric used to describe the value of future national energy savings is the net present value (NPV). The NPV accounts for both the present value of national electricity savings and the present value of national equipment costs.

For purposes of this analysis, the likely standard is based on the combination of design options that result in a minimum or near minimum life-cycle cost. Based on the life-cycle cost results presented in Section 3.31 (Table 3.8), an EER of $2.92 \mathrm{~W} / \mathrm{W}$ is chosen as the most likely standard. As stated previously, the cost-efficiency analysis could only be conducted for split air conditioners, heat pump-type, with cooling capacities between 2500 to 4500 Watts. But since this product class represents a majority of equipment sales in China, national impacts are approximated by applying the cost-efficiency results for this product class to all air conditioner types.

\subsubsection{National Energy Savings}

National annual energy savings are calculated as the difference between two projections: a base case (without new standards) and a standards case (as shown in the equation below). Positive 
values of NES correspond to energy savings (i.e., energy consumption with standards is less than energy consumption in the base case).

$$
N E S_{y}=A E C_{\text {base }}-A E C_{s \tan \text { dard }}
$$

Cumulative energy savings are the sum over some period (e.g., 2001-2020) of the annual national energy savings.

$$
N E S_{\text {cum }}=\sum N E S_{y}
$$

The national annual energy consumption is calculated according to the following equation:

$$
A E C=\sum\left[S T O C K_{V} \cdot U E C_{V}\right]
$$

For the above expressions, the following quantities are defined as:

$$
\begin{array}{ll}
\text { NES }= & \text { Annual national energy savings (tons of coal equivalent (tce)). } \\
A E C= & \begin{array}{l}
\text { Annual energy consumption each year (tce), summed over vintages of air } \\
\text { conditioner stocks, } S T O C K_{V} .
\end{array} \\
S T O C K_{V}= & \begin{array}{l}
\text { Stock of air conditioners (millions of units) of vintage } V \text { surviving in the } \\
\text { year for which annual energy consumption is being calculated. Vintages }
\end{array} \\
& \text { range from } 1-\text { to } 16 \text {-years old. }
\end{array}
$$

The following sections describe in detail the inputs required to generate the national energy savings.

\subsubsection{Annual Energy Consumption per Unit (UEC)}

Assuming the hours of operation remain constant, the annual energy consumed per unit varies from year to year based on the level of efficiency of new units being shipped. The analysis conducted for this report assumes that a nationally representative annual energy consumption is tied to a nationally representative equipment efficiency and is determined according to the following expression:

where,

$$
U E C_{v}=U E C_{R E F} \cdot \frac{E E R_{R E F}}{E E R_{v}}
$$


$U E C_{V}=\quad$ Annual energy consumption of an air conditioner in a particular vintage year, $U E C_{R E F}=$ annual energy consumption of the reference air conditioner,

$E E R_{V}=\quad$ energy efficiency of an air conditioner in a particular vintage year, and

$E E R_{R E F}=$ energy efficiency of the reference air conditioner.

The baseline unit modeled in the cost-efficiency analysis serves as the basis for both the reference annual energy consumption and the reference energy efficiency. As presented earlier in Table 3.8, the baseline EER $\left(E E R_{R E F}\right)$ equals $2.27 \mathrm{~W} / \mathrm{W}$ and the corresponding annual energy consumption $\left(U E C_{R E F}\right)$ equals $426 \mathrm{kWh} /$ year.

The base case forecast of national energy consumption assumes that the baseline EER (2.27 $\mathrm{W} / \mathrm{W}$ ) and corresponding annual energy consumption ( $426 \mathrm{kWh} / \mathrm{year}$ ) are representative of units produced in China in 1989. (The minimum energy efficiency standards enacted in 1989 are close to the baseline efficiency of $2.27 \mathrm{~W} / \mathrm{W}$.) In 1998 a large percentage of air conditioner models exhibited EERs of at least $2.70 \mathrm{~W} / \mathrm{W}$ (Figure 2.5). Thus, for the year 1998 the nationally representative EER of air conditioners are assumed to equal $2.70 \mathrm{~W} / \mathrm{W}$. Table 3.10 shows the nationally representative EERs and corresponding UECs that are assumed between the years 1989 and 1998. For the years between 1989 and 1998, representative EERs are interpolated.

Table 3.10 Nationally Representative EERs and UECs

\begin{tabular}{|c|c|c|}
\hline & EER & UEC \\
\hline Year & $W / W$ & $k W h /$ year \\
\hline 1989 (reference year) & 2.27 & 426 \\
\hline 1990 & 2.32 & 417 \\
\hline 1991 & 2.37 & 409 \\
\hline 1992 & 2.41 & 401 \\
\hline 1993 & 2.46 & 393 \\
\hline 1994 & 2.51 & 386 \\
\hline 1995 & 2.56 & 378 \\
\hline 1996 & 2.60 & 371 \\
\hline 1997 & 2.65 & 365 \\
\hline 1998 & 2.70 & 358 \\
\hline
\end{tabular}

For all years beyond 1998, the base case forecast assumes that the nationally representative efficiency of air conditioners remains at $2.70 \mathrm{~W} / \mathrm{W}$.

The standards case forecast of national energy consumption assumes the identical EERs and UECs as the base case forecast up to the effective date of the new energy efficiency standard. The assumed effective date of the new standard is the year 2001. As stated earlier, the new air conditioner standard is assumed to equal $2.92 \mathrm{~W} / \mathrm{W}$ with a corresponding annual energy consumption of $332 \mathrm{kWh} /$ year. The standards case forecast assumes that the nationally representative efficiency of air conditioners remains at $2.92 \mathrm{~W} / \mathrm{W}$ for years beyond 2001.

\subsubsection{Shipments}


Shipments are critical to the forecast of national energy consumption. The number of shipments per year dictates the stock of air-conditioning equipment in the country. As is evident from Table 3.11, significant domestic production and sales did not occur in China until the early 1990's. Thus, the amount of energy required for space-cooling in China was fairly insignificant. But with the dramatic increase in sales that has occurred during the last decade, China now must supply energy for an ever growing air conditioning demand. As of 1998 it was estimated that over 39 million air conditioners existed in China. Table 3.11 provides a detailed look of the domestic production, import, export, and domestic shipments or sales of air conditioners since 1978 (SSB 1999; China Customs 1999). It is estimated that up through 1996, all domestically available air conditioners were being sold within China. Since 1997, it is estimated that $90 \%$ of domestically available air conditioners are being sold within China (with the remainder being inventoried).

Table 3.11 Chinese Domestic Shipments

\begin{tabular}{|c|c|c|c|c|c|c|}
\hline & $\begin{array}{l}\text { Domestic } \\
\text { Production }\end{array}$ & Import & Export & $\begin{array}{c}\text { Trade } \\
\text { Balance }\end{array}$ & $\begin{array}{l}\text { Domestic } \\
\text { Available }\end{array}$ & $\begin{array}{c}\text { Domestic } \\
\text { Shipments (Sales) }\end{array}$ \\
\hline Year & thousands & thousands & thousands & thousands & thousands & thousands \\
\hline 1978 & 5 & - & - & - & 5 & 5 \\
\hline 1979 & 9 & - & - & - & 9 & 9 \\
\hline 1980 & 13 & - & - & - & 13 & 13 \\
\hline 1981 & 14 & - & - & - & 14 & 14 \\
\hline 1982 & 24 & - & - & - & 24 & 24 \\
\hline 1983 & 35 & - & - & - & 35 & 35 \\
\hline 1984 & 61 & - & - & - & 61 & 61 \\
\hline 1985 & 124 & - & - & - & 124 & 124 \\
\hline 1986 & 97 & - & - & - & 97 & 97 \\
\hline 1987 & 132 & - & - & - & 132 & 132 \\
\hline 1988 & 259 & - & - & - & 259 & 259 \\
\hline 1989 & 375 & - & - & - & 375 & 375 \\
\hline 1990 & 241 & - & - & - & 241 & 241 \\
\hline 1991 & 630 & 32 & 25 & -7 & 637 & 637 \\
\hline 1992 & 1,580 & 84 & 58 & -26 & 1,606 & 1,606 \\
\hline 1993 & 2,918 & 194 & 93 & -101 & 3,020 & 3,020 \\
\hline 1994 & 3,826 & 342 & 223 & -119 & 3,945 & 3,945 \\
\hline 1995 & 5,190 & 225 & 350 & 125 & 5,065 & 5,065 \\
\hline 1996 & 7,860 & 127 & 500 & 373 & 7,487 & 7,487 \\
\hline 1997 & 9,740 & 32 & 841 & 809 & 8,931 & 8,038 \\
\hline 1998 & 11,570 & 29 & 1,193 & 1,164 & 10,406 & 9,366 \\
\hline $1999^{1}$ & 12,000 & - & 1,300 & 1,300 & 10,700 & 9,630 \\
\hline
\end{tabular}

${ }^{1}$ Production, imports, exports, and sales are estimated.

\subsubsection{Stock of Air Conditioners $\left(\mathrm{STOCK}_{V}\right)$}

In determining the national energy consumption for both the base case and standards case forecasts, it is required to keep a track of the number of air conditioners surviving in any particular year. Air conditioners are assumed to have an increasing probability of retiring as they age. The probability of survival as a function of years since purchase is called the survival function. The survival function for this analysis, of which the lifetime of the equipment is based, is constructed around an assumed average air conditioner lifetime of 12.5 years. Figure 3.4 shows the assumed 
survival function. As is evident from Figure 3.4, all air conditioners are assumed to expire by their $16^{\text {th }}$ year.

Figure 3.4 Survival Function of Air Conditioners

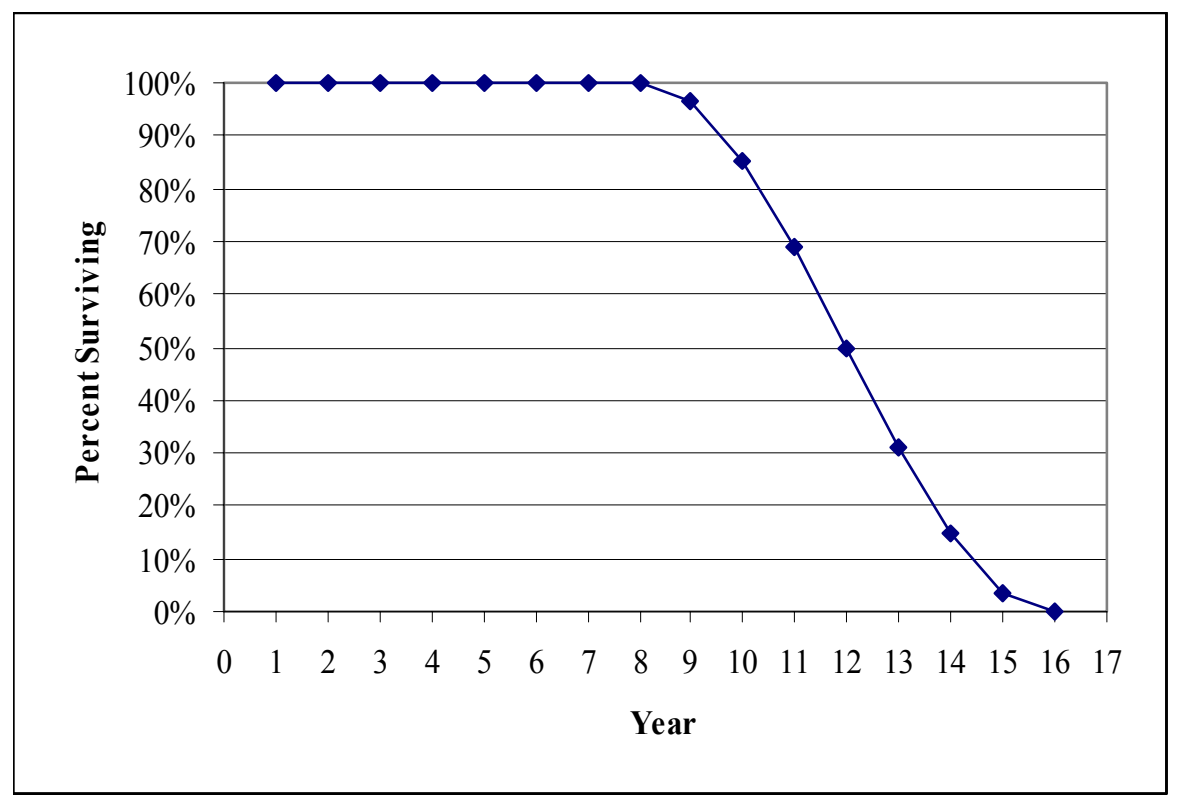

\subsubsection{Source Conversion Factors}

For electricity, this is the factor by which site $\mathrm{kWh}$ is multiplied to obtain primary (source) energy (in tons of coal equivalent (tce)). The source conversion factor accounts for losses in generation, transmission and distribution and permits comparison across fuels by taking account of the heat content of different fuels and the efficiency of different energy conversion processes.

To convert from site $\mathrm{kWh}$ to source tce, the source conversion factor is applied to site electricity. This analysis assumes that the source conversion factor changes over time. Table 3.12 and Figure 3.5 present the average conversion factors (SSB 1998a). For years beyond 1996, the site-tosource conversion factor is assumed to remain unchanged and equal 410 grams coal equivalent per kWh (gce/kWh). 
Table 3.12 Site-to-Source Conversion Factors

\begin{tabular}{|c|c|}
\hline & Site-to-Source Conversion Factor \\
\hline Year & gce/kWh \\
\hline 1978 & 471 \\
\hline 1979 & 457 \\
\hline 1980 & 448 \\
\hline 1981 & 442 \\
\hline 1983 & 438 \\
\hline 1984 & 434 \\
\hline 1985 & 432 \\
\hline 1986 & 431 \\
\hline 1987 & 432 \\
\hline 1988 & 432 \\
\hline 1999 & 431 \\
\hline 1991 & 432 \\
\hline 1992 & 427 \\
\hline 1993 & 427 \\
\hline 1994 & 420 \\
\hline 1995 & 417 \\
\hline & 414 \\
\hline & 413 \\
\hline
\end{tabular}

Figure 3.5 Site-to-Source Conversion Factors

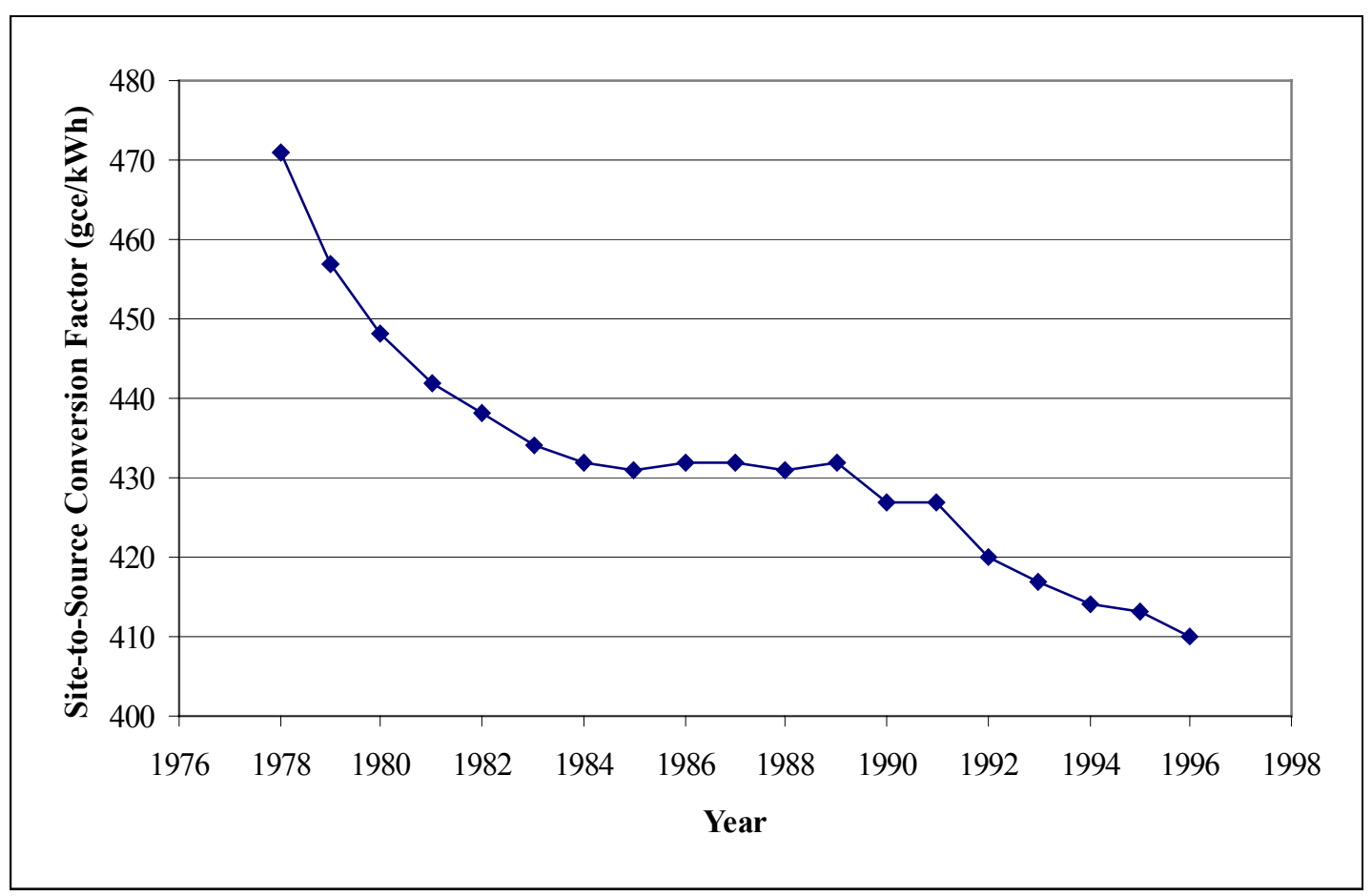




\subsubsection{Net Present Value}

Net present value (NPV) is the value in the present time of a time series of costs and savings. Net present value is described by the equation:

where,

$$
N P V=P V S-P V C
$$

$P V S=$ present value of electricity savings and

$P V C=$ present value of equipment costs including installation.

$P V S$ and $P V C$ are determined according to the following expressions:

$$
\begin{gathered}
P V S_{y}=\sum\left[\operatorname{TOCS}_{y} \cdot D F_{y}\right] \\
P V C_{y}=\sum\left[\text { TEC }_{y} \cdot D F_{y}\right]
\end{gathered}
$$

where,

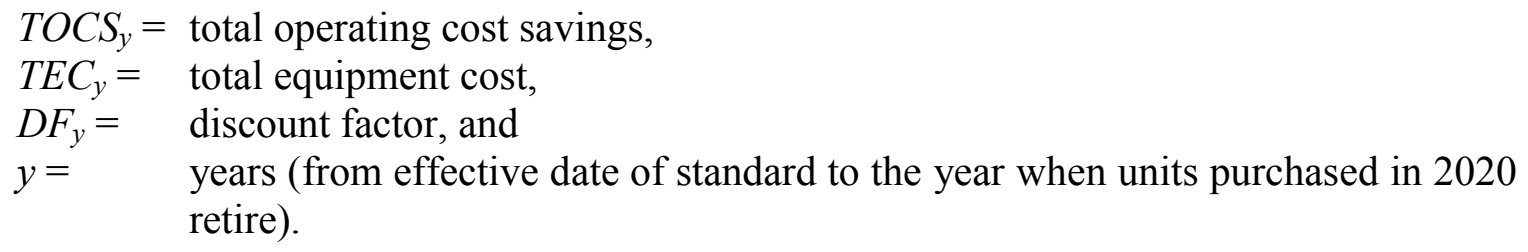

The net present value is calculated from the projections of national expenditures for air conditioners, including purchase price (including equipment and installation price) and operating costs (including electricity costs). Costs and savings are calculated as the difference between a new standards case and a base case without those new standards. Future costs and savings are discounted to the present.

A discount factor is calculated from the discount rate and the number of years between the "present" (year to which the sum is being discounted) and the year in which the costs and savings occur. The net present value is the sum over time of the discounted net savings. The discount factor is determined according to the following expression:

where,

$$
D F=\frac{1}{(1+D R)^{(f y r-p y r)}}
$$

$D R=$ discount rate,

$f y r=$ future year, and

pyr $=$ present year (i.e., year in which to discount future costs or savings).

For this analysis, the discount rate is assumed to be $6 \%$ real.

Assumptions regarding $N P V$ are contained in the terms $P V C$ and $P V S$. Total operating cost savings (TOCS) and total equipment cost (TEC), which comprise $P V S$ and $P V C$, respectively, are discussed below. $N P V$ is the value today of a future stream of savings less expenditures. 


\subsubsection{Total Operating Cost Savings}

Annual national total operating cost savings are calculated as the difference between total operating cost in the base case minus total operating cost in the standards case. The result is multiplied by the projected shipments in that year. Positive values are savings (e.g., operating costs in the standards case are lower than in the base case).

Operating costs for the purposes of this analysis consist of only annual electricity costs (repair and maintenance costs are not accounted for). Annual electricity costs for any given year are based upon the annual energy consumption per unit for that year (see Section 3.4.1.1, Annual Energy Consumption per Unit (UEC)) multiplied by the associated electricity price. The electricity price is assumed to equal $0.6 \mathrm{Yuan} / \mathrm{kWh}(7.2 \mathrm{cents} / \mathrm{kWh}$ in U.S. dollars) for all years.

\subsubsection{Total Equipment Cost}

Annual national total equipment cost changes are calculated as the difference in equipment price (difference between base case and standards case). The result is multiplied by the projected shipments in that year.

Equipment prices are based on the prices developed in the cost-efficiency analysis (refer to Table 3.8). Table 3.13 summarizes the equipment prices that correspond to the nationally representative equipment efficiencies that were presented earlier in Table 3.10. The baseline equipment price of 4445 Yuan corresponds to the baseline EER of $2.27 \mathrm{~W} / \mathrm{W}$. The equipment price corresponding to an EER of $2.70 \mathrm{~W} / \mathrm{W}$ (the representative efficiency for 1998) is arrived at by interpolating between the equipment prices for design options 3 and 4 in Table 3.8. The remaining prices in Table 3.13 for the years between 1989 and 1998 are arrived at through interpolation.

Table 3.13 Nationally Representative Equipment Prices and Efficiencies

\begin{tabular}{|c|c|c|c|}
\hline & \multicolumn{2}{|c|}{ Equipment Price } & EER \\
\hline Year & Yuan & U.S. $\$$ & $W / W$ \\
\hline 1989 (reference year) & 4445 & 536 & 2.27 \\
\hline 1990 & 4457 & 537 & 2.32 \\
\hline 1991 & 4469 & 538 & 2.37 \\
\hline 1992 & 4481 & 540 & 2.41 \\
\hline 1993 & 4493 & 541 & 2.46 \\
\hline 1994 & 4505 & 543 & 2.51 \\
\hline 1995 & 4517 & 544 & 2.56 \\
\hline 1996 & 4529 & 546 & 2.60 \\
\hline 1997 & 4541 & 547 & 2.65 \\
\hline 1998 & 4553 & 549 & 2.70 \\
\hline
\end{tabular}

The equipment price corresponding to the assumed efficiency standard of $2.92 \mathrm{~W} / \mathrm{W}$ comes directly from Table 3.8 and equals 4637 Yuan (\$559 U.S.). 


\subsubsection{National Energy Savings and Net Present Value Results}

The national energy savings resulting from an EER standard of $2.92 \mathrm{~W} / \mathrm{W}$ are presented in Table 3.14 and Figure 3.6. By the year 2020, cumulative energy savings of over 18 million tce can be realized through the standard.

Table 3.14 National Energy Savings from an EER standard of 2.92 W/W

\begin{tabular}{|c|c|c|}
\hline & Annual Energy Savings & Cumulative Energy Savings \\
\hline Year & 1000 tce & 1000 tce \\
\hline 2001 & 104 & 104 \\
\hline 2002 & 209 & 313 \\
\hline 2003 & 313 & 626 \\
\hline 2004 & 417 & 1,044 \\
\hline 2005 & 522 & 1,565 \\
\hline 2006 & 626 & 2,192 \\
\hline 2007 & 731 & 2,922 \\
\hline 2008 & 835 & 3,757 \\
\hline 2009 & 939 & 4,696 \\
\hline 2010 & 1,040 & 5,736 \\
\hline 2011 & 1,129 & 6,865 \\
\hline 2012 & 1,201 & 8,066 \\
\hline 2013 & 1,253 & 9,319 \\
\hline 2014 & 1,285 & 10,604 \\
\hline 2015 & 1,301 & 11,905 \\
\hline 2016 & 1,304 & 13,209 \\
\hline 2017 & 1,304 & 14,514 \\
\hline 2018 & 1,304 & 15,818 \\
\hline 2019 & 1,304 & 17,123 \\
\hline 2020 & 1,304 & 18,427 \\
\hline
\end{tabular}

Figure 3.6 National Energy Savings from an EER standard of 2.92 W/W

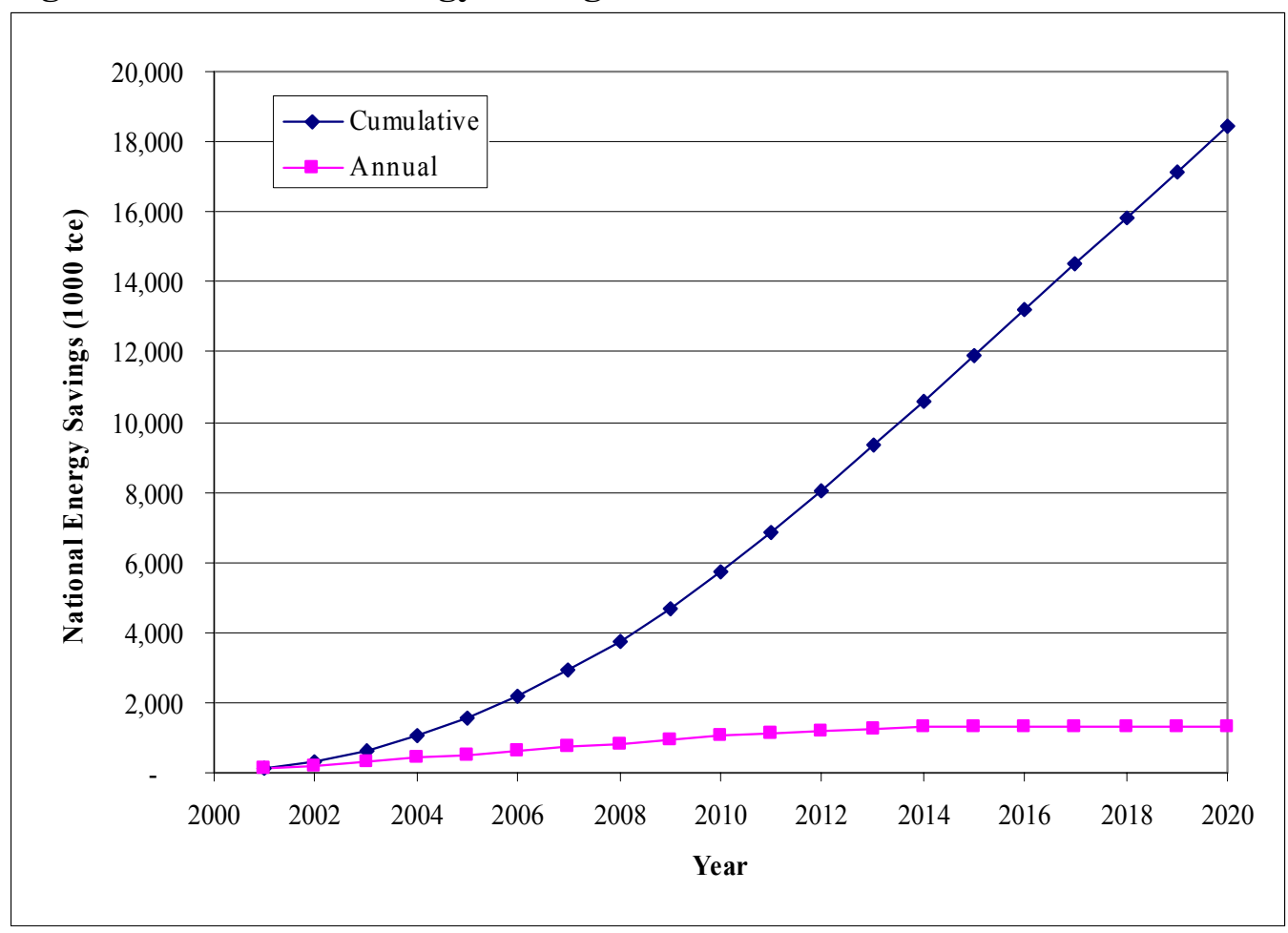


Table 3.15 summarizes the national net present value resulting from an EER standard of 2.92 W/W. A net present benefit of over 3.5 billion Yuan (over $\$ 400$ million U.S.) can be realized between the years 2000 to 2020 .

Table 3.15 Net Present Value of an EER standard of 2.92 W/W

\begin{tabular}{|l|c|c|}
\hline \multirow{2}{*}{$\begin{array}{l}\text { Discounted at 6\% to year 1998 } \\
\text { from 2000 to 2020 }\end{array}$} & China & U.S. \\
\hline Total Operating Cost Savings & $11,773,644$ & Thousand dollars \\
\hline Total Equipment Costs & $8,251,382$ & $1,418,511$ \\
\hline Net Present Value & $3,522,262$ & 994,142 \\
\hline Benefit to Cost Ratio & 1.43 & 424,369 \\
\hline
\end{tabular}

\subsection{Environmental Impact Analysis}

As world economy continues to grow and atmospheric pollution worsens, the environmental impact of air conditioner use is of increasing concern to the global community. In 1998, air conditioner electricity consumption in China accounted for approximately $6 \%$ of residential electricity usage, thus, contributing to increased pollutant emissions to the atmosphere.

This section presents the forecasted reduction in Carbon emissions at fossil-fueled electric power plants due to the increased energy efficiency of air conditioners in China. Forecasted reductions are based on converting the estimated national energy savings resulting from an EER standard of $2.92 \mathrm{~W} / \mathrm{W}$ (Table 3.14) with an emission factor of 650 metric tons of Carbon per thousand tce (tons of coal equivalent) (SSB 1998b).

Table 3.16 and Figure 3.7 present both the Carbon and $\mathrm{CO}_{2}$ savings resulting from an EER standard of $2.92 \mathrm{~W} / \mathrm{W} . \mathrm{CO}_{2}$ savings were determined with an emission factor of 2382 metric tons of $\mathrm{CO}_{2}$ per thousand tce. 
Table 3.16 National $\mathrm{CO}_{2}$ and Carbon Savings from an EER standard of $2.92 \mathrm{~W} / \mathrm{W}$

\begin{tabular}{|c|c|c|c|c|c|c|}
\hline & \multicolumn{2}{|c|}{ Energy Savings } & \multicolumn{2}{c|}{$\mathbf{C O}_{2}$ Savings } & \multicolumn{2}{c|}{ Carbon Savings } \\
\hline & Annual & Cumulative & Annual & Cumulative & Annual & Cumulative \\
\hline Year & 1000 tce & 1000 tce & $k t$ & $k t$ & $k t$ & $k t$ \\
\hline 2001 & 104 & 104 & 249 & 249 & 68 & 68 \\
\hline 2002 & 209 & 313 & 497 & 746 & 136 & 204 \\
\hline 2003 & 313 & 626 & 746 & 1,492 & 204 & 407 \\
\hline 2004 & 417 & 1,044 & 995 & 2,487 & 271 & 678 \\
\hline 2005 & 522 & 1,565 & 1,244 & 3,731 & 339 & 1,018 \\
\hline 2006 & 626 & 2,192 & 1,492 & 5,223 & 407 & 1,425 \\
\hline 2007 & 731 & 2,922 & 1,741 & 6,964 & 475 & 1,899 \\
\hline 2008 & 835 & 3,757 & 1,990 & 8,954 & 543 & 2,442 \\
\hline 2009 & 939 & 4,696 & 2,239 & 11,193 & 611 & 3,053 \\
\hline 2010 & 1,040 & 5,736 & 2,478 & 13,671 & 676 & 3,728 \\
\hline 2011 & 1,129 & 6,865 & 2,691 & 16,361 & 734 & 4,462 \\
\hline 2012 & 1,201 & 8,066 & 2,862 & 19,223 & 781 & 5,243 \\
\hline 2013 & 1,253 & 9,319 & 2,986 & 22,210 & 814 & 6,057 \\
\hline 2014 & 1,285 & 10,604 & 3,064 & 25,273 & 836 & 6,893 \\
\hline 2015 & 1,301 & 11,905 & 3,100 & 28,373 & 845 & 7,738 \\
\hline 2016 & 1,304 & 13,209 & 3,109 & 31,482 & 848 & 8,586 \\
\hline 2017 & 1,304 & 14,514 & 3,109 & 34,591 & 848 & 9,434 \\
\hline 2018 & 1,304 & 15,818 & 3,109 & 37,700 & 848 & 10,282 \\
\hline 2019 & 1,304 & 17,123 & 3,109 & 40,810 & 848 & 11,130 \\
\hline 2020 & 1,304 & 18,427 & 3,109 & 43,919 & 848 & 11,978 \\
\hline
\end{tabular}

Figure 3.7 National Carbon and $\mathrm{CO}_{2}$ Savings form an EER standard of 2.92 W/W

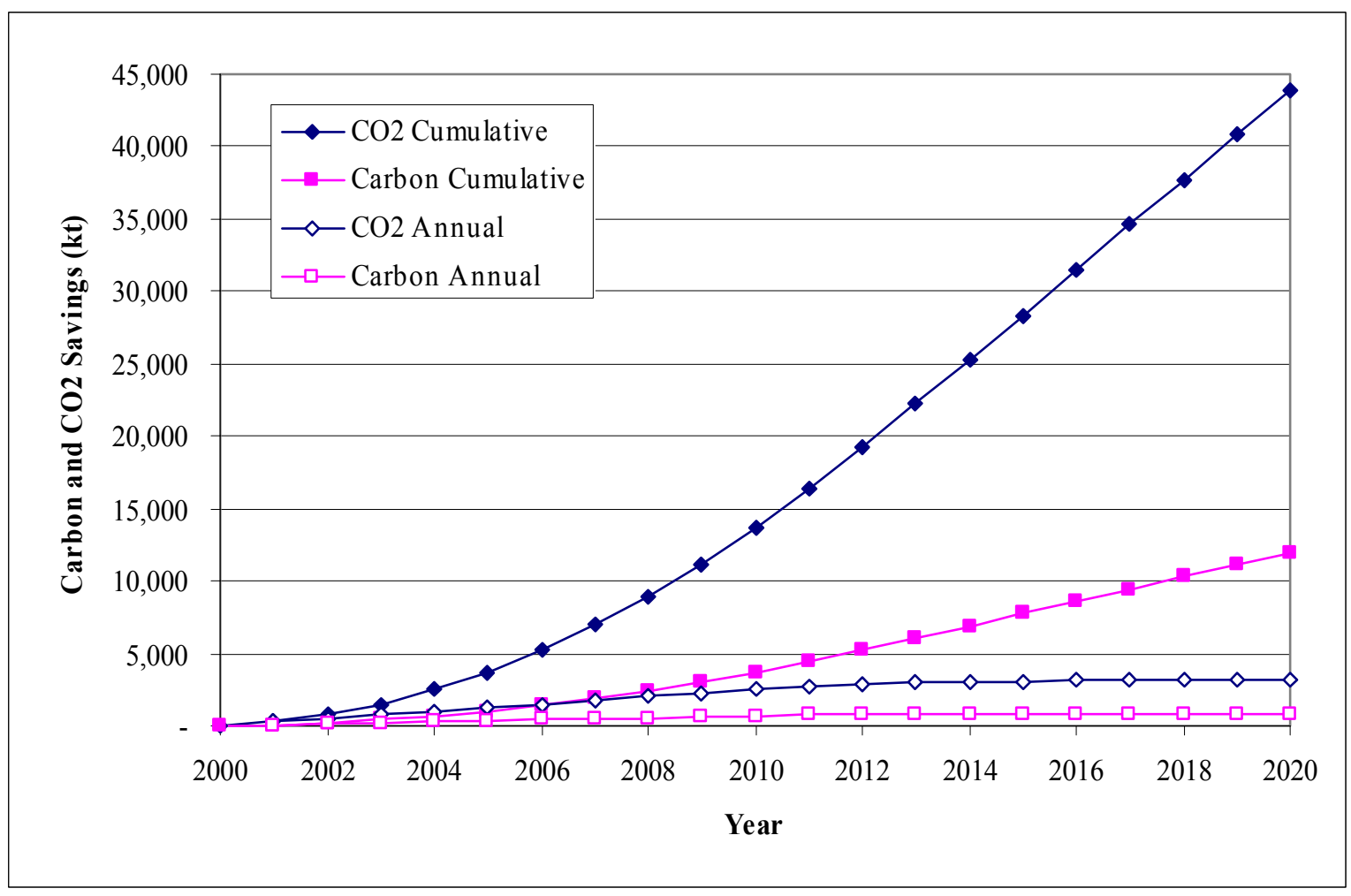


Reduced electricity generation would also incur other environmental benefits, such as water pollution and land use, but such factors are not taken into consideration in this analysis. 


\subsection{Summary}

This analysis evaluated the technical feasibility and economic impact of air conditioner energy conservation potential in China. Specifically, the analysis evaluated feasibility of various technical options to raise air conditioner efficiency, their cost-effectiveness, and national impacts on energy consumption and the environment. Through a thorough investigation and comparison, it becomes apparent that raising the energy efficiency of air conditioners in China would have significant impact on energy demand, economic development, and environmental protection. As China's economy continues to grow and scientific knowledge continues to improve, raising air conditioner energy efficiency over time is both feasible and cost-effective.

Future analysis will focus on collecting more technical data on air conditioner performance, extend the scope of engineering and economic analyses to other air conditioner product classes, revise the results of the engineering and economic analyses, and determine the most cost-effective energy efficiency levels for different types of air conditioner product classes. 


\section{Appendix A: Baseline Unit Description Data}

\section{A.1 Physical Description of Baseline Unit}

The following provides the physical description of the baseline unit for the split system product class with cooling capacities between 2500 to 4500 Watts. The following input data is necessary for being able to simulate the performance of the unit with the Oak Ridge National Laboratory (ORNL) Heat Pump Design Model. The following data were provided by a Chinese air conditioner manufacturer and represents the characteristics of an actual model available for sale in the Chinese market. 


\begin{tabular}{|c|c|}
\hline \multicolumn{2}{|l|}{ UNIT DATA: } \\
\hline Capacity (Watts) * & 3500 \\
\hline $\operatorname{EER}(W / W) *$ & 2.7 \\
\hline \multicolumn{2}{|l|}{ COMPRESSOR DATA: } \\
\hline Compressor type (single, two, variable-speed) & $\mathrm{S}$ \\
\hline Manufacturer & National \\
\hline Manufacturer Model number & $2 \mathrm{k} 23$ \\
\hline \multicolumn{2}{|l|}{ Motor: } \\
\hline Nominal size $(h p) *$ & 1300 \\
\hline Nominal frequency $(\mathrm{Hz}) *$ & 50 \\
\hline Nominal voltage (volts) $*$ & 220 \\
\hline \multicolumn{2}{|l|}{ Compressor map data: } \\
\hline Total Displacement (cc/rev) * & 23.2 \\
\hline Superheat/Return Gas temp $\left({ }^{\circ} \mathrm{C}\right) *$ & \\
\hline Attach compressors maps $*$ & \\
\hline
\end{tabular}

\begin{tabular}{|ll|}
\hline ACCUMULATOR GEOMETRY: & \\
\hline Accumulator Height $(\mathrm{mm})$ & 180 \\
Accumulator Internal Diameter $(\mathrm{mm})$ & 75 \\
\hline
\end{tabular}

\begin{tabular}{|ll|}
\hline EVAPORATOR COIL DATA: & \\
\hline Frontal area $\left(\mathrm{m}^{2}\right) *$ & 0.1732 \\
Number of parallel circuits * & 2 \\
Refrigerant Tubing: & 2 \\
$\quad$ Number of tube rows in air flow direction & 2.1 \\
$\quad$ Parallel spacing $(\mathrm{cm}) *$ & 1.27 \\
Perpendicular spacing $(\mathrm{cm}) *$ & 11 \\
Total number of tubes & 10 \\
Total number of return bends & 0.7 \\
Outside Diameter $(\mathrm{cm})$ & 0.646 \\
Inside Diameter $(\mathrm{cm})$ & $\mathrm{G}$ \\
Tube type (smooth or grooved) & \\
If tube type is grooved: & \\
$\quad$ Refrigerant-side heat transfer enhancement $*$ & \\
$\quad$ Refrigerant-side pressure drop multiplier $*$ & \\
Fins: & \\
Pitch (fins/cm) & 0.14 \\
Thickness $(\mathrm{cm})$ & 0.012 \\
Fin type (flat, wavy, slit, louvered) * & $\mathrm{S}$ \\
If fin type is wavy, slit, or louvered: & \\
$\quad$ Air-side heat transfer enhancement * & \\
Air-side coil pressure drop multiplier * & \\
\hline
\end{tabular}

\begin{tabular}{|ll|}
\hline EVAPORATOR BLOWER DATA: \\
\hline Fan motor type (Shaded Pole, PSC) & PSC \\
Nominal blower frequency $(\mathrm{Hz}) *$ & 50 \\
Nominal air flow rate $\left(\mathrm{m}^{3}\right) *$ & 0.133 \\
Fan efficiency $(\%) *$ & \\
Fan-motor efficiency $(\%) *$ & 30 \\
\hline
\end{tabular}

\section{REFRIGERANT LINE DATA:}

Liquid Line:

Pressure Drop at nominal mass flow $(\mathrm{Pa})$ *

Suction Line:

Pressure Drop at nominal mass flow $(\mathrm{Pa}) *$

Discharge Line:

Pressure Drop at nominal mass flow $(\mathrm{Pa}) *$

Nominal Mass Flow Rate:

For above pressure drops $(\mathrm{kg} / \mathrm{s}) *$

\begin{tabular}{|ll|}
\hline FLOW CONTRL DEVICE DATA: & \\
\hline Device type (Capillary Tube, Orifice, TXV) & $\mathrm{C}$ \\
If Capillary Tube: & \\
Inside Diameter $(\mathrm{mm})$ & 1.6 \\
Number of tubes in parallel & 500 \\
If Short Tube Orifice: & \\
Diameter ( $\mathrm{mm}$ ) & \\
If Thermostatic Expansion Valve: & \\
Rated capacity (Watts) & \\
\hline
\end{tabular}

\section{CONDENSER COIL DATA:}

\begin{tabular}{|ll|}
\hline Frontal area $\left(\mathrm{m}^{2}\right) *$ & 0.42 \\
Number of parallel circuits * & 2 \\
Refrigerant Tubing: & \\
$\quad$ Number of tube rows in air flow direction & 2 \\
Parallel spacing $(\mathrm{cm}) *$ & 2.5 \\
Perpendicular spacing $(\mathrm{cm}) *$ & 2.17 \\
Total number of tubes & 24 \\
Total number of return bends & 24 \\
Outside Diameter $(\mathrm{cm})$ & 0.9 \\
Inside Diameter $(\mathrm{cm})$ & 0.83 \\
Tube type (smooth or grooved) & $\mathrm{S}$ \\
If tube type is grooved: & \\
$\quad$ Refrigerant-side heat transfer enhancement $*$ & \\
$\quad$ Refrigerant-side pressure drop multiplier $*$ & \\
Fins: & \\
Pitch (fins $/ \mathrm{cm})$ & 0.15 \\
Thickness $(\mathrm{cm})$ & 0.014 \\
Fin type (flat, wavy, slit, louvered) $*$ & $\mathrm{~W}$ \\
If fin type is wavy, slit, or louvered: & \\
$\quad$ Air-side heat transfer enhancement * & \\
Air-side coil pressure drop multiplier $*$ & \\
\hline
\end{tabular}

\section{CONDENSER FAN DATA:}

Fan motor type (Shaded Pole, PSC) PSC

Nominal blower frequency $(\mathrm{Hz}) * \quad 50$

Nominal air flow rate $\left(\mathrm{m}^{3}\right) * \quad 0.416$

Fan efficiency $(\%) *$

Fan-motor efficiency (\%) * 28 


\section{A.2 Test Data of Baseline Unit}

The following provides the performance data for the baseline unit described in section A.1. The test data are based upon the baseline unit tested at the ISO $5151 \mathrm{~T} 1$ condition. 


\section{TEST DATA FOR BASELINE UNIT}

Data below to be based on actual testing under ISO $5151 \mathrm{~T} 1$ test condition.

\section{GENREAL INFORMATION}

\begin{tabular}{|ll|}
\hline Measured Capacity (Watts) & 3460 \\
Measured Electrical Power Input (Watts) & 1305 \\
Refrigerant Charge (kg) & 1.3 \\
\hline
\end{tabular}

TEMPERATURES AND PRESSURES

\begin{tabular}{|c|c|c|c|c|c|}
\hline Location & $\begin{array}{c}\text { Refrigerant } \\
\text { Temperature } \\
\left({ }^{\circ} \mathrm{C}\right)\end{array}$ & $\begin{array}{l}\text { Refrigerant } \\
\text { Pressure } \\
(M P a)\end{array}$ & $\begin{array}{c}\text { Dry Bulb Air } \\
\text { Temperature } \\
\left({ }^{\circ} \mathrm{C}\right)\end{array}$ & $\begin{array}{c}\text { Wet Bulb Air } \\
\text { Temperature } \\
\left({ }^{\circ} \mathrm{C}\right)\end{array}$ & $\begin{array}{c}\text { Air Relative } \\
\text { Humidity } \\
(\%)\end{array}$ \\
\hline \multicolumn{6}{|l|}{ Compressor: } \\
\hline Shell Inlet & 15 & 0.58 & ----NA----- & -----NA----- & -----NA----- \\
\hline Shell Outlet & 85 & 1.95 & -----NA----- & -----NA----- & -----NA----- \\
\hline Superheat at Inlet & 10 & -----NA----- & -----NA----- & -----NA----- & -----NA----- \\
\hline \multicolumn{6}{|l|}{ Condenser Coil: } \\
\hline Inlet & 70 & 1.92 & 35 & 24 & 40 \\
\hline Outlet & 42 & 1.87 & 45 & & 27 \\
\hline Subcooling & 6.5 & -----NA----- & -----NA----- & -----NA----- & -----NA----- \\
\hline \multicolumn{6}{|l|}{ Expansion Device: } \\
\hline Inlet & 41 & 1.85 & -----NA----- & -----NA----- & -----NA----- \\
\hline \multicolumn{6}{|l|}{ Evaporator Coil: } \\
\hline Inlet & 12 & 0.7 & 27 & 19 & 48 \\
\hline Outlet & 7 & 0.58 & 13 & 11.5 & 80 \\
\hline
\end{tabular}

PRESSURE DROPS

\begin{tabular}{|lcc|}
\hline Location & Air-Side & Refrigerant-Side \\
$(\mathrm{Pa})$ & $(\mathrm{Pa})$ \\
\hline Evaporator Coil & & 0.12 \\
Condenser Coil & & 0.05 \\
\hline
\end{tabular}

AIR FLOW

\begin{tabular}{|lcc|}
\hline Location & $\begin{array}{c}\text { Air Flow } \\
\left(\mathrm{m}^{3} / \mathrm{s}\right)\end{array}$ & $\begin{array}{c}\text { Face Velocity } \\
(\mathrm{m} / \mathrm{s})\end{array}$ \\
\hline Evaporator Blower & 0.133 & 0.75 \\
Condenser Fan & 0.416 & 0.99 \\
\hline
\end{tabular}

COMPRESSOR AND FAN MOTOR: POWER, SPEED, AND FREQUENCY

\begin{tabular}{|lccc|}
\hline \multicolumn{1}{|c}{ Type } & $\begin{array}{c}\text { Power } \\
(\text { Watts })\end{array}$ & $\begin{array}{c}\text { Motor Speed } \\
(\mathrm{rpm})\end{array}$ & $\begin{array}{c}\text { Motor Frequency } \\
(\mathrm{Hz})\end{array}$ \\
\hline Compressor & 1300 & 2860 & 50 \\
Evaporator Fan Motor & 32 & 1180 & 50 \\
Condenser Fan Motor & 75 & 690 & 50 \\
\hline
\end{tabular}




\section{A.3 Simulation Input File for Baseline Unit}

The following provides an annotated ORNL Heat Pump Design model input data file for the baseline unit.

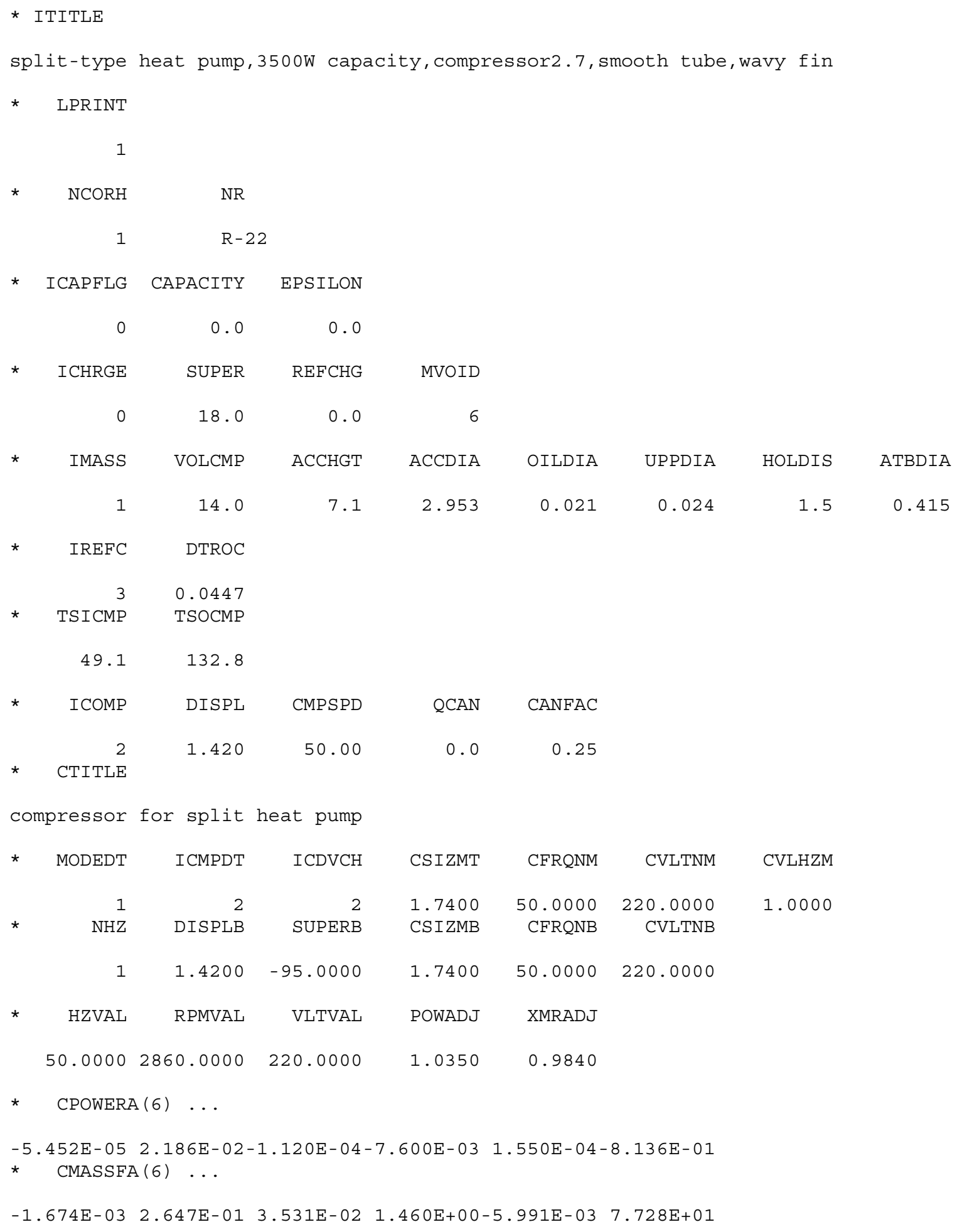




\begin{tabular}{|c|c|c|c|c|c|c|c|c|}
\hline \multirow[t]{2}{*}{ * } & TAIII & RHII & & & & & & \\
\hline & 80.6 & 0.50 & & & & & & \\
\hline * & & & \multicolumn{6}{|c|}{ IRFIDF } \\
\hline * & FRQIDF & FRQNMI & QANMI & SIZMTI & FANEFI & $\wedge$ ICHIDF & DDUCT & FIXCAP \\
\hline & 1.0 & 50.0 & 281.8 & 0.0 & 0.0868976 & -1 & 6.0 & 0.0 \\
\hline \multirow[t]{2}{*}{ * } & $A A F I$ & NTI & NSECTI & WTI & STI & RTBI & & \\
\hline & 1.864 & 2.0 & 2.00 & 0.394 & 0.825 & 10.0 & & \\
\hline \multirow[t]{2}{*}{ * } & FINTYI & FPI & DELTAI & DEAI & DERI & $\mathrm{XKFI}$ & XKTI & HCONTI \\
\hline & 1.0 & 16.7 & 0.005 & 0.2756 & 0.2543 & 128.3 & 225.0 & 100.0 \\
\hline \multirow[t]{2}{*}{ * } & NDUM & XDUM & & & & & & \\
\hline & 0 & 0.0 & & & & & & \\
\hline \multirow[t]{2}{*}{ * } & HTRMLI & PDRMLI & HTAMLI & PDAMLI & CABMLI & & & \\
\hline & 1.0 & 1.0 & 1.12 & 1.05 & 1.0 & & & \\
\hline \multirow[t]{2}{*}{ * } & TAIIO & RHIO & & & & & & \\
\hline & 95.0 & 0.40 & & & & & & \\
\hline \multicolumn{3}{|c|}{ * } & \multicolumn{6}{|c|}{ IRFODF } \\
\hline \multirow[t]{2}{*}{ * } & FRQODF & FRQNMO & QANMO & SIZMTO & FANEFO & $\wedge$ ICHODF & MFANFT & \\
\hline & 1.0 & 50.0 & 881.5 & 0.0 & 0.0566456 & $\begin{array}{ll}-1 & -1\end{array}$ & 0 & \\
\hline \multirow[t]{2}{*}{ * } & AAFO & NTO & NSECTO & WTO & STO & RTBO & & \\
\hline & 4.52 & 2.0 & 2.0 & 0.854 & 0.983 & 24.0 & & \\
\hline \multirow[t]{2}{*}{ * } & FINTYO & FPO & DELTAO & DEAO & DERO & $\mathrm{XKFO}$ & хкто & HCONTO \\
\hline & 1.0 & 15.5 & 0.005 & 0.3543 & 0.3268 & 128.3 & 225.0 & 100.0 \\
\hline \multirow[t]{2}{*}{ * } & NDUM & XDUM & & & & & & \\
\hline & 0 & 0.0 & & & & & & \\
\hline \multirow[t]{2}{*}{ * } & HTRMLO & PDRMLO & HTAMLO & PDAMLO & CABMLO & & & \\
\hline & 1.0 & 1.0 & 1.11 & 1.05 & 1.0 & & & \\
\hline \multirow[t]{2}{*}{ * } & MCMPOP & MFANIN & MFANOU & & & & & \\
\hline & 2 & 2 & 2 & & & & & \\
\hline \multirow[t]{2}{*}{ * } & QSUCLN & QDISLN & QLIQLN & DPSLN & DPDLN & DPLLN & XMRNOM & \\
\hline & -14.4 & 100.0 & 10.0 & 0.0 & 0.0 & 0.0 & 0.0 & \\
\hline * & DLL & XLEQLL & DLRVIC & XLRVIC & DLRVOC & XLRVOC & & \\
\hline
\end{tabular}




\begin{tabular}{|c|c|c|c|c|c|c|c|c|}
\hline & 0.2885 & 16.00 & 0.7260 & 16.00 & 0.7260 & 2.00 & & \\
\hline \multirow[t]{2}{*}{ * } & DSLRV & XLEQLP & DDLRV & XLEQHP & & & & \\
\hline & 0.7260 & 5.00 & 0.4760 & 2.00 & & & & \\
\hline * & $\mathrm{AMBCON}$ & CNDCON & FLOCON & EVPCON & CONMST & CMPCON & TOLH & TOLS \\
\hline & 0.0 & 0.0 & 0.0 & 0.0 & 0.0 & 0.0 & 0.0 & 0.0 \\
\hline
\end{tabular}




\section{References}

Adnot, J., M. Orphelin, C. Lopes, P. Waide. 2000. "Limiting the Impact of Increasing Cooling Demand in the European Union: Results from a Study on Room Air-Conditioner Energy Efficiency," Proceedings: 2000 ACEEE Summer Study on Energy Efficiency in Buildings, Washington, DC: American Council for an Energy-Efficient Economy.

ASHRAE. 1998. 1998 ASHRAE Handbook, Refrigeration, American Society of Heating, Refrigerating, and Air-Conditioning Engineers, Inc., Atlanta, GA, p. 45.9.

Bahel, V. and S.M. Zubair. 1989. "An Assessment of Inverter-Driven Variable-Speed Air Conditioners: Sample Performance Comparison with a Conventional System." ASHRAE Transactions. 95(1): pp 455-464.

CECA. 1999. Zhongguo Kongtiao Hangye Diaocha (Sector Study of Room Air Conditioners in China), China Energy Conservation Association, Beijing, China, December 1999.

China Customs Bureau. 1999. Zhongguo Haiguan Nianjian (China Customs Yearbook), China Customs Bureau, Beijing, China (various years).

CLIIC. 1998. Zhongguo Kongtiao Qi Shichang (China's Air Conditioner Market), China Light Industry Information Center, Beijing, China, 28 October 1998.

Fischer, S.K., and C.K. Rice. 1983. The Oak Ridge Heat Pump Models: I. Steady-State Computer Design Model for Air-to-Air Heat Pumps. ORNL/CON-80/R1. Oak Ridge, Tenn.: Oak Ridge National Laboratory.

Fischer, S.K., C.K. Rice, and W.L. Jackson. 1988. The Oak Ridge Heat Pump Design Model: Mark III Version Program Documentation. ORNL/TM-10192. Oak Ridge, Tenn.: Oak Ridge National Laboratory.

Henderson, H.I., Jr. 1990. "A Side-by-Side Field Test of Variable-Speed and Constant-Speed Air Conditioners." ASHRAE Transactions. 96(1): pp 683-692.

Hori, M., I. Akamine, and T. Sakai. 1985. "Seasonal Efficiencies of Residential Heat Pump Air Conditioners with Inverter-Driven Compressors." ASHRAE Transactions. 91(2B): pp 15851595.

ISO, International Organization for Standardization. 1994. ISO 5151: Non-ducted air conditioners and heat pumps - Testing and rating for performance, First Edition. ISO 5151:1994(E). Genève, Switzerland: International Organization for Standardization. 
Kang Haogao, ed.. 1995. Zuixin Kongtiao Zhileng Shebei Anzhuang Shiyong Weixiu Daquan (Compendium on the Installation, Use, and Repair of the Newest Air Conditioning Equipment). Seismic Publishing House, Beijing, 1995.

Mimakim M.. 1987. "Effectiveness of Finned-Tube Heat Exchanger Coated Hydrophilic-Type Film." ASHRAE Transactions, 93(1): pp 62-71.

Ogilvy Public Relations. 1999. China Energy Efficient Air-Conditioner Study, 22 October 1999, Beijing, China.

ORNL, Oak Ridge National Laboratory. 1996. ORNL Heat Pump Design Model, Mark V, Version 95d. Oak Ridge National Laboratory, Oak Ridge, Tennessee.

SBTS, State Bureau of Technical Supervision, 1989. Limited values of energy consumption and method of testing for room air conditioners. GB 12021.3-89. State Bureau of Technical Supervision, Beijing, China.

SBTS, State Bureau of Technical Supervision, 1996. Room Air Conditioners. GB/T7725. State Bureau of Technical Supervision, Beijing, China.

SSB, State Statistical Bureau. 1998a. Zhongguo Gongye Jingji Tongji Nianjian (China Industrial Economic Statistics Yearbook). State Statistical Bureau, Beijing China.

SSB, State Statistical Bureau, 1998b. Zhongguo Nengyuan Tongji Nianjian (China Energy Statistical Yearbook). State Statistical Bureau, Beijing, China.

SSB, State Statistical Bureau. 1999. Zhongguo Tongji Nianjian 1999 (China Statistical Yearbook, 1999). State Statistical Bureau, Beijing China.

Takebayashi, M., K. Sekigami, I. Tsubono, H. Kohsokabe, K. Suefuji, and K. Inaba. 1994. "Performance Improvement of a Variable-Speed Controlled Scroll Compressor for Household Air Conditioners." ASHRAE Transactions, 100(1): pp 471-475.

US DOE, U.S. Department of Energy. 1997. Technical Support Document for Energy Conservation Standards for Room Air Conditioners (Docket Numbers EE-RM-90-201 \& EE-RM-93801-RAC), Volume 2 - Detailed Analysis of Efficiency Levels. Prepared by Lawrence Berkeley National Laboratory, Energy \& Environment Division, Berkeley, CA for U.S. Department of Energy, Office of Codes and Standards. Page 1-51.

Zhou Zicheng, ed. 1997. Fangjian Kongtiao Qi de Yuanli he Anzhuang Weixiu (Principles of Room Air Conditioners and Installation and Repair), Machine Building Industry Publishing House, Beijing, May 1996. 